\title{
Tall fescue endophyte effects on tolerance to water-deficit stress
}

\author{
Padmaja Nagabhyru', Randy D Dinkins ${ }^{2}$, Constance L Wood ${ }^{3}$, Charles W Bacon ${ }^{4}$ and Christopher L Schardl ${ }^{*}$
}

\begin{abstract}
Background: The endophytic fungus, Neotyphodium coenophialum, can enhance drought tolerance of its host grass, tall fescue. To investigate endophyte effects on plant responses to acute water deficit stress, we did comprehensive profiling of plant metabolite levels in both shoot and root tissues of genetically identical clone pairs of tall fescue with endophyte $(E+)$ and without endophyte (E-) in response to direct water deficit stress. The $\mathrm{E}$ - clones were generated by treating $\mathrm{E}+$ plants with fungicide and selectively propagating single tillers. In time course studies on the $\mathrm{E}+$ and $\mathrm{E}$ - clones, water was withheld from 0 to 5 days, during which levels of free sugars, sugar alcohols, and amino acids were determined, as were levels of some major fungal metabolites.

Results: After 2-3 days of withholding water, survival and tillering of re-watered plants was significantly greater for $\mathrm{E}+$ than $\mathrm{E}$ - clones. Within two to three days of withholding water, significant endophyte effects on metabolites manifested as higher levels of free glucose, fructose, trehalose, sugar alcohols, proline and glutamic acid in shoots and roots. The fungal metabolites, mannitol and loline alkaloids, also significantly increased with water deficit.

Conclusions: Our results suggest that symbiotic N. coenophialum aids in survival and recovery of tall fescue plants from water deficit, and acts in part by inducing rapid accumulation of these compatible solutes soon after imposition of stress.
\end{abstract}

Keywords: Fungal endophyte, Tall fescue, Water deficit stress, Metabolites, Neutral sugars, Amino acids and lolines

\section{Background}

Tall fescue (Lolium arundinaceum $=$ Schedonorus arundinaceus $=$ Festuca arundinacea) is the most widely planted forage grass in the United States [1] and it is often infected with the endophytic fungus, Neotyphodium coenophialum. The relationship between the endophyte and plant is generally considered mutualistic because the endophyte significantly improves host plant tolerance to drought, insects, diseases, and nematodes, along with increased persistence and vigor; and in turn the plant provides the symbiont with nutrients, protection, and reliable and efficient dissemination (reviewed in [2]). Evidence suggests that tall fescue plants with the endophyte $(\mathrm{E}+)$ grow and persist longer under stressful conditions, such as water deficit, compared to endophyte free plants (E-), and are, therefore, likely to have an adaptive and competitive advantage [3-9]. Mechanisms for endophyte-enhanced drought avoidance or

\footnotetext{
* Correspondence: Schardl@uky.edu

'Department of Plant Pathology, University of Kentucky, Lexington, KY 40546-0312, USA

Full list of author information is available at the end of the article
}

tolerance appear complex, and might involve direct and indirect effects of the endophyte on metabolism and other physiological changes in the host plant [10-13].

Processes affected by the tall fescue endophyte include stomatal closure [14], decreased root diameter and increased root hair length $[7,15]$, increased turgid weight/ dry weight ratios suggesting reduced damaged to cell walls [10], and enhanced production of phenolic root exudates [15]. Leaf rolling under drought stress is reported to be much more common in E+than E- plants [3]. Greater cell wall elasticity [10] and higher water use efficiency [16] in E+ tall fescue compared to E- plants under drought stress have also been reported. Previous research has also shown that E+ tall fescue plants of some genotypes exhibit lower stomatal conductance than E- plants with more sensitive inducement of stomatal closure in E+ plants in response to early stages of water deficit [17-19]. Endophyte infection confers population stability in tall fescue during drought stress through improved tiller and whole plant survival [5].

\section{Biomed Central}


A correlation between drought tolerance and accumulation of compatible solutes such as carbohydrates, amino acids, and mineral ions that contribute to osmotic adjustment has been documented in grasses [20-22]. In general, accumulation of sugars, sugar alcohols [23], and proline $[24,25]$ in response to water deficit in grasses has been reported. A significant endophyte effect on accumulation of simple sugars in leaves of E+ tall fescue, was observed when plants were osmotically stressed by polyethylene glycol [26]. Under water deficit, E+ tall fescue plants are reported to exhibit decreased growth and increased root and leaf senescence, as well as greater accumulation of sugars within the pseudostem, and decreased water potential compared to E- plants [27]. Effects of the endophyte on levels of other metabolites, such as proline [28] and other amino acids have not been well studied. Here we report what is, to our knowledge, the first comprehensive profiling of shoot and root metabolite responses to acute water deficit stress, assessing the timing of endophyte effects on sugars, sugar alcohols and amino acids relative to the endophyte effects on subsequent plant recovery.

\section{Methods}

\section{Experimental design}

Tall fescue is an obligately outcrossing grass, so that isogenic lines cannot be generated, and plants derived from different seeds are necessarily unique genotypes. Therefore, to control for host genotype effects we developed genetically identical clones with endophyte $(\mathrm{E}+)$ and without endophyte (E-) as follows. Ramets of tall fescue 'Kentucky 31' plants naturally infected with Neotyphodium coenophialum were treated with the fungicide propiconazole or tebuconazole to remove the fungus $[29,30]$. The stock plants and fungicide-treated clones were examined for the presence or absence of endophyte by tissue print immunoblot [31], PCR [32], and microscopy. This resulted in $\mathrm{E}+\mathrm{E}$ - clone pairs, two of which were used in this study. Lab identification numbers $278(\mathrm{E}+)$ and 279 (E-) represented one clone pair, and 4607 (E+) and 4608 (E-) represented the other clone pair. Plants of each clone pair were raised side-by-side in the greenhouse for more than one year prior to being used in the study.

Ramets consisting of three tillers of similar size were planted into $8.5 \times 8.5 \mathrm{~cm}$ square pots in sand, in the greenhouse. Sand was chosen as the growth medium because it allows even, uniform and rapid drying, and also provides for easy harvesting of roots. Plants were watered twice daily for six weeks before subjecting them to experimental conditions to allow for regeneration and accumulation of sufficient biomass for sampling. After sufficient re-growth had occurred, water was withheld from the test group, while control plants were watered twice daily. Pots were randomized once while setting up the experiment and again before subjecting them to treatments, in order to control for effects microenvironmental variation.

Treatments were endophyte-infected watered controls $(\mathrm{E}+\mathrm{D}-)$, endophyte-infected water-deficit stressed (E+ $\mathrm{D}+$ ), endophyte-free watered controls (E-D-), and endophytefree water-deficit stressed $(E-D+)$. Entire pots were sampled on each day from day 0 to day 5 of withholding water. Beyond day 5 plants were fully dried and mostly dead. Three or four replicates were sampled for each treatment $\mathrm{x}$ day. For the first experiment, which was conducted with the $278 / 279$ clone pair, samples were harvested from February 2-7, 2007. For the second experiment with clone pair $278 / 279$, samples were harvested from June 2-7, 2008. The third experiment was conduced with clone pair 4607/4608, sampled from July 21-26, 2008. All plants were grown in the greenhouse under natural light conditions, with $45-70 \%$ relative humidity ranges, and temperatures set to $27^{\circ} \mathrm{C} / 22^{\circ} \mathrm{C}$ (day/night). Photoactive radiation (PAR) measurements were recorded during the three experiments (see Additional file 1, panels a, b, c). Samples were harvested between 7:30 a.m. to 8:30 a.m. local time each day, immediately frozen in liquid nitrogen, lyophilized and subsequently prepared for metabolite analysis as described below. The samples were divided into shoot (leaf along with tiller base down to $1 \mathrm{~cm}$ from crown region) and root material.

\section{Tiller recovery experiment}

Five to six pots subjected to water-deficit conditions from each E+/E- clone pair for each day of treatment were left unharvested, and were placed back into a daily watering regime in order to determine their ability to recover from the water-deficit stress. Live tiller numbers were counted after 6 weeks of recovery.

\section{Carbohydrate analysis by high $\mathrm{pH}$ anion exchange chromatography}

Sugars were extracted in $1 \mathrm{ml}$ of $80 \%$ ethanol per $100 \mathrm{mg}$ of ground lyophilized plant material. The samples were incubated at $65^{\circ} \mathrm{C}$ for $1 \mathrm{hr}$ and $90^{\circ} \mathrm{C}$ for $5 \mathrm{~min}$ and the supernatant was evaporated in a vacuum centrifuge. The residue was reconstituted in purified water at $4^{\circ} \mathrm{C}$ and filtered through spin-X HPLC $0.4 \mu \mathrm{m}$ nylon filter micro centrifuge (Corning, NY) tubes. Filtered supernatant $(100 \mu \mathrm{L})$ was diluted to $1 \mathrm{ml}$ and used for analysis on a Dionex ICS 3000 with either a carbopac PA1 column for neutral sugars or a carbopac MA1 column for polyols. Neutral sugars were separated by an isocratic program with $24 \mathrm{mM} \mathrm{NaOH}$, and sugar alcohols were separated using $480 \mathrm{mM} \mathrm{NaOH}$. The detection was by pulsed amperometry, using a gold working electrode. Peak identity and sugar quantity 
were determined by comparison with standards. The internal standard was 2-deoxyglucose.

\section{Amino acid analysis by liquid chromatography-mass spectrometry (LC-MS)}

The yields of free amino acids from plant samples were compared for different extraction methods using a) $80 \%$ ethanol, or b) chloroform: methanol: water (5:12:3), and incubating at different temperatures $\left(4^{\circ} \mathrm{C}\right.$ and $\left.45^{\circ} \mathrm{C}\right)$ for $1 \mathrm{hr}$. However both extraction solvents and methods resulted in similar extraction efficiency, so the simpler extraction method was chosen for further analysis. Finely ground lyophilized plant shoot and root material $(50 \mathrm{mg})$ was extracted with $5 \mathrm{ml}$ of $80 \%$ ethanol on ice for $1 \mathrm{hr}$. The crude extract was filtered through $0.4 \mu \mathrm{m}$ centrifuge tubes and the supernatant was used for sample cleanup and derivatization with EZ faast LCMS kit for free amino acids from Phenomenex, according to the kit protocol. Briefly, $100 \mu \mathrm{L}$ of each sample was mixed with $100 \mu \mathrm{L}$ of internal standard containing homoarginine, d3methionine, and homophenylalanine provided in the kit. Then sample was loaded onto a pipet tip packed with ion exchange resin on which free amino acids were bound, subsequently washed and released from resin. The free amino acids were then derivatized by propyl chloroformate and liquid-liquid extracted with isooctane. The organic phase containing the derivatized amino acids was removed under a stream of high purity nitrogen gas and the residue was redissolved in $200 \mu \mathrm{L}$ 2:1 mobile phase of A:B (A: $10 \mathrm{mM}$ ammonium formate in water and $\mathrm{B}: 10 \mathrm{mM}$ ammonium formate in methanol). Analysis was performed by liquid chromatography mass spectrometry with a dual pump ProStar 210 HPLC with 1200 L quadrupole MS-MS (Varian).

\section{Loline alkaloid analysis}

Loline alkaloids were extracted from samples using chloroform under alkaline conditions [33]. Quinoline was used as an internal standard and the lolines were quantified by gas chromatography (Varian CP-3800) interfaced with a Varian Saturn 2200 ion trap mass spectrometer. Loline amounts were calculated as the total of loline, $\mathrm{N}$-methylloline, $\mathrm{N}$-formylloline, $\mathrm{N}$-acetylloline and $\mathrm{N}$ acetylnorloline.

\section{Statistical analysis}

Factorial Analysis of Variance $(2 \times 2 \times 6)$ was run to analyze tiller recovery and metabolite levels in PROC GLM, SAS (SAS Institute Inc., Cary, NC, USA.). Following ANOVA, tiller recovery and metabolite levels of E+ and E- clones were compared on each day using Estimate Statements. In order to control the overall $\alpha$-level for multiple tests, the distribution of the maximum of the absolute value of elements of a multivariate (six variate) t-distribution with $\boldsymbol{\mu}=$ $\mathbf{0}$ and $\Sigma=\mathbf{I}$ [34], i.e. t-max, was used to calculate the significance levels for each of the six t-tests. Because of the extremely conservative nature of this procedure, $\alpha=0.10$ is used to determine significance of differences [p. 71 in ref. [35]. The three factor ANOVAs of all metabolites in all three experiments are given in Tables 1, 2, and 3. For the tiller numbers after recovery, four biological replications were run for each treatment in the first experiment on clone pair 278/279, and five biological replications were run for the other two experiments on clone pair 278/279 and clone pair 4607/4608. For metabolites, four biological replications were run for each treatment in the first experiment, and three biological replications were run for the other two experiments. In the graphs the significant differences of various metabolites between E+ and E- plants in the water deficit stress treatments were represented based on t-max values; ${ }^{* * \prime}$ denotes $p$-values $=>0.01-0.10$; $*$ **; denotes $p$-values $>0.001-0.01$; ${ }^{\text {(***) }}$ denotes $p$-values $<0.001$.

\section{Results}

\section{Tiller number and recovery}

Overall the E+ plants survived the stress conditions imposed during the experiment better than the E- plants when number of tillers produced upon recovery was used as the measure. In the first experiment with clone pair 278/279, after 2-4 days of withholding water, E+ plants produced more tillers than E- plants during recovery. However, after 5 days withholding water, none of the E+ or E- plants recovered (Figure 1a). In the second experiment with the same clone pair, starting at 3 days of withholding water, tiller recovery was significantly higher in E+ clones (Figure 1b). With clone pair 4607/4608 (Figure 1c), after 3-days of water deficit there was greater tillering of $\mathrm{E}+$ plants, which was marginally significant $\left(p=0.110\right.$ based on $\mathrm{t}_{\max }, p=0.019$ based on $t$ values).

\section{Neutral sugars}

The levels of galactose, glucose, fructose, sucrose, raffinose, stachyose, and trehalose were quantified in the tall fescue clone pairs in response to water deficit stress and endophyte infection. Of these, glucose, fructose and sucrose were the major free sugars identified. In Experiment 1 with clone pair 278/279, E+ shoots accumulated approximately 2 -fold more free glucose and free fructose at day 1 compared to E- shoots (Figures $2 \mathrm{a}$ and $3 \mathrm{a}$ ). Similarly in roots, free glucose and free fructose levels in $\mathrm{E}+$ clones at day 1 after withholding water were significantly higher than in the E- clones (Figures $2 \mathrm{~b}$ and $3 \mathrm{~b}$ ). In contrast, at day $1, \mathrm{E}+$ and $\mathrm{E}$ - clones showed no difference in sucrose levels compared to watered controls. Sucrose levels increased in shoots and roots of both $\mathrm{E}+$ and E- clones starting from day 2 after withholding water (Figure 4a and b, Table 1). Comparing combined 
Table 1 Three-factor ANOVA $\left[F_{d f(5,72)}\right]$ values of all metabolites in Experiment 1

\begin{tabular}{|c|c|c|c|c|c|c|c|}
\hline Metabolite & Endophyte & Day & Stress & Day * Endophyte & Stress * Endophyte & Stress * Day & Endophyte * Stress * Day \\
\hline Shoot glucose & $48.89^{* * *}$ & $54.96 * * *$ & $36.91 * * *$ & $6.05^{* * *}$ & 2.37 & $7.13^{* * *}$ & $39.52^{* * *}$ \\
\hline Shoot fructose & $6.77^{*}$ & $35.59 * * *$ & $143.32^{* * *}$ & $4.64^{* * *}$ & 0.88 & $9.37^{* * *}$ & $8.75^{* * *}$ \\
\hline Shoot sucrose & $13.18^{* * *}$ & $13.97^{* * *}$ & $113.23^{* * *}$ & 2.38 & 0.23 & $15.59^{* * *}$ & $2.58^{* *}$ \\
\hline Shoot GFS & 1.72 & $37.69^{* * *}$ & $206.12^{* * *}$ & 0.96 & 0 & $9.72^{* * *}$ & $9.85^{* * *}$ \\
\hline Shoot proline & 0.2 & $148.29^{* * *}$ & $178.23^{* * *}$ & $12.33^{* * *}$ & $4.50^{* *}$ & $145.27^{* * *}$ & $16.86^{* * *}$ \\
\hline Shoot glutamine & 0.03 & $26.92 * * *$ & $33.29^{* * *}$ & $3.61^{* *}$ & 0.26 & $6.16^{* * *}$ & $3.24^{* *}$ \\
\hline Shoot glutamic acid & $6.55^{*}$ & $64.80^{* * *}$ & $61.02^{* * *}$ & $3.56^{* *}$ & $11.03^{* * *}$ & $9.48^{* * *}$ & $5.88^{* * *}$ \\
\hline Shoot asparagine & 0.8 & $8.27^{* * *}$ & $25.16^{* * *}$ & 2.11 & 0.24 & $8.49^{* * *}$ & $2.70^{*}$ \\
\hline Shoot aspartic acid & 0.98 & $19.41^{* * *}$ & 0.49 & $3.37^{* *}$ & 0.14 & $10.01^{* * *}$ & $10.11^{* * *}$ \\
\hline Shoot tryptophan & $20.09^{* * *}$ & $40.29^{* * *}$ & $533.71^{* * *}$ & $2.60^{*}$ & 0.02 & $41.42^{* * *}$ & $9.05^{* * *}$ \\
\hline Shoot phenylalanine & $9.94^{* *}$ & $78.52^{* * *}$ & $564.58^{* * *}$ & $7.90^{* * *}$ & $36.25^{* * *}$ & $56.47^{* * *}$ & $17.66^{* * *}$ \\
\hline Shoot tyrosine & $34.61^{* * *}$ & $19.69^{* * *}$ & $67.21^{* * *}$ & $9.91 * * *$ & $5.33^{*}$ & $15.41^{* * *}$ & $9.73^{* * *}$ \\
\hline Shoot lolines & $1930.18^{* * *}$ & $3.11^{*}$ & $17.84^{* * *}$ & $3.11^{*}$ & $17.84^{* * *}$ & $9.97^{* * *}$ & $9.97^{* * *}$ \\
\hline Root glucose & 0.4 & $17.57^{* * *}$ & 0.38 & $10.03^{* * *}$ & $7.12^{* * *}$ & $6.16^{* * *}$ & $14.24^{* * *}$ \\
\hline Root fructose & 0.2 & $27.72 * * *$ & $22.17^{* * *}$ & $5.39^{* * *}$ & $4.93^{*}$ & $18.99^{* * *}$ & $15.73^{* * *}$ \\
\hline Root sucrose & 0.02 & $9.19^{* * *}$ & $36.32^{* * *}$ & 1.97 & 0.02 & $8.71^{* * *}$ & $4.75^{* * *}$ \\
\hline Root GFS & 0.13 & $12.59^{* * *}$ & $25.81^{* * *}$ & $5.22^{* * *}$ & $4.10^{*}$ & $5.80^{* * *}$ & $6.04^{* * *}$ \\
\hline Root proline & 1.37 & $16.07 * * *$ & $209.87^{* * *}$ & $7.74^{* * *}$ & 0.17 & $18.11^{* * *}$ & $6.19^{* * *}$ \\
\hline Root glutamine & $5.51^{*}$ & $29.58^{* * *}$ & $27.53^{* * *}$ & $18.69^{* * *}$ & 3.17 & $6.67^{* * *}$ & 1.35 \\
\hline Root glutamic acid & $7.13^{* *}$ & $50.81^{* * *}$ & $86.53^{* * *}$ & $23.01^{* * *}$ & 0 & $5.57^{* * *}$ & $14.41^{* * *}$ \\
\hline Root asparagine & $40.63^{* * *}$ & $5.21^{* * *}$ & $43.23^{* * *}$ & $3.09^{*}$ & 0.75 & $2.87^{*}$ & 1.7 \\
\hline Root aspartic acid & $5.55^{*}$ & $32.52^{* * *}$ & $18.15^{* * *}$ & $7.71^{* * *}$ & $5.69^{*}$ & $10.40^{* * *}$ & $10.25^{* * *}$ \\
\hline Root tryptophan & $6.35^{*}$ & $4.88^{* * *}$ & 0.23 & 1.75 & 0.63 & 2.14 & $3.40^{*}$ \\
\hline Root phenylalanine & $18.44^{* * *}$ & $20.94^{* * *}$ & $8.01^{* *}$ & $9.37^{* * *}$ & $10.26^{* *}$ & $7.83^{* * *}$ & $3.00^{*}$ \\
\hline Root tyrosine & $13.03^{* * *}$ & $7.95^{* * *}$ & 0.03 & $4.07^{* *}$ & $8.11^{* *}$ & $2.64^{*}$ & 2.32 \\
\hline Root lolines & $1914.28^{* * *}$ & $3.64^{* *}$ & $35.14^{* * *}$ & $3.64^{* *}$ & $35.14^{* * *}$ & 1.64 & 1.64 \\
\hline
\end{tabular}

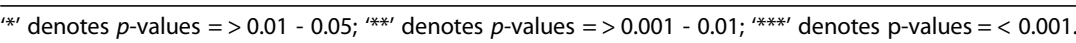


Table 2 Three-factor ANOVA [ $\left.F_{d f}(5,48)\right]$ values of all metabolites in Experiment 2

\begin{tabular}{|c|c|c|c|c|c|c|c|}
\hline Metabolite & Endophyte & Day & Stress & Day * Endophyte & Stress * Endophyte & Stress * Day & Endophyte * Stress * Day \\
\hline Shoot glucose & $42.30^{* * *}$ & $11.03 * * *$ & $15.13^{* * *}$ & 0.61 & 1.84 & $2.93^{*}$ & $3.08^{*}$ \\
\hline Shoot fructose & $39.02^{* * *}$ & $14.48^{* * *}$ & $21.23^{* * *}$ & 1.45 & 2.6 & $3.69^{* *}$ & $3.35^{* *}$ \\
\hline Shoot sucrose & $17.26^{* * *}$ & $16.55^{* * *}$ & 0.01 & 2.33 & 0.12 & $3.51^{* *}$ & 0.68 \\
\hline Shoot GFS & $37.84^{* * *}$ & $15.85^{* * *}$ & $8.37^{* *}$ & 0.67 & 1.38 & $2.98^{*}$ & 1.67 \\
\hline Shoot proline & $25.90^{* * *}$ & $124.48^{* * *}$ & $581.24^{* * *}$ & $7.46^{* * *}$ & $25.52^{* *}$ & $126.22^{* * *}$ & $7.31^{* * *}$ \\
\hline Shoot glutamine & $11.43^{* *}$ & $42.89 * * *$ & $113.19^{* * *}$ & $2.39^{*}$ & 0.05 & $28.25^{* * *}$ & 1.09 \\
\hline Shoot glutamic acid & 0 & $7.19^{* * *}$ & $34.68^{* * *}$ & 0.4 & 0.44 & $6.66^{* * *}$ & 0.34 \\
\hline Shoot asparagine & $10.25^{* *}$ & $12.48^{* * *}$ & $79.38^{* * *}$ & 1.05 & 1.16 & $18.03^{* * *}$ & 0.38 \\
\hline Shoot aspartic acid & 2.37 & $7.66^{* * *}$ & $6.45^{*}$ & 1.47 & 0.12 & $5.49^{* * *}$ & 0.22 \\
\hline Shoot threonine & 0.19 & $48.84^{* * *}$ & $260.74^{* * *}$ & 1.97 & 3.46 & $58.15^{* * *}$ & 0.95 \\
\hline Shoot tryptophan & 0.88 & $80.90^{* * *}$ & $245.37^{* * *}$ & 0.61 & 2.66 & $60.11^{* * *}$ & 0.75 \\
\hline Shoot phenylalanine & 0.27 & $91.52^{* * *}$ & $431.11^{* * *}$ & 0.12 & 1.4 & $88.98^{* * *}$ & 0.31 \\
\hline Shoot tyrosine & $17.32^{* * *}$ & $18.31^{* * *}$ & $204.79 * * *$ & $3.35^{*}$ & 2.16 & $38.27 * * *$ & 0.92 \\
\hline Shoot lolines & $486.57^{* * *}$ & 2.21 & $15.81^{* * *}$ & 2.21 & $15.81^{* * *}$ & $3.05^{*}$ & $3.05^{*}$ \\
\hline Shoot mannitol & $89.37^{* * *}$ & $19.68^{* * *}$ & $18.41^{* * *}$ & $13.54^{* * *}$ & $16.47^{* * *}$ & $4.22^{* *}$ & $3.84^{* *}$ \\
\hline Shoot arabitol & $15.72^{* * *}$ & $6.25^{* * *}$ & $26.29 * * *$ & $3.26^{* *}$ & $21.25^{* * *}$ & $5.66^{* * *}$ & $3.77^{* * *}$ \\
\hline Shoot sorbitol & $10.36^{* *}$ & $4.01^{* *}$ & 3.67 & 0.85 & 1.48 & 1.87 & 1 \\
\hline Shoot myo-inositol & $4.98^{*}$ & $17.81^{* * *}$ & $14.50^{* * *}$ & 1.3 & 0.66 & $4.28^{* *}$ & 1.2 \\
\hline Shoot trehalose & $13.11^{* * *}$ & $21.50^{* * *}$ & $5.65^{*}$ & 0.71 & $7.38^{* *}$ & $7.35^{* * *}$ & 0.8 \\
\hline Root glucose & $28.46^{* * *}$ & $5.10^{* * *}$ & $20.44^{* * *}$ & $2.61^{*}$ & $5.14^{*}$ & $3.97^{* *}$ & $2.33^{*}$ \\
\hline Root fructose & $37.16^{* * *}$ & $23.23 * * *$ & $11.34^{* * *}$ & $4.24^{* *}$ & $29.11^{* * *}$ & 1.77 & 1.85 \\
\hline Root sucrose & $5.67^{*}$ & $6.50 * * *$ & $28.68^{* * *}$ & $5.83^{* * *}$ & $5.99^{*}$ & $3.86^{* *}$ & $2.36^{*}$ \\
\hline Root GFS & $11.09^{* *}$ & $14.02^{* * *}$ & 0.05 & $3.90^{* *}$ & $20.57^{* * *}$ & 2.03 & $2.92^{*}$ \\
\hline Root proline & $46.51^{* * *}$ & $28.74 * * *$ & $121.16^{* * *}$ & $10.55^{* * *}$ & $43.90^{* * *}$ & $29.80^{* * *}$ & $11.07^{* * *}$ \\
\hline Root glutamine & 3.18 & $10.28^{* * *}$ & $38.96^{* * *}$ & 1.26 & 0.61 & $8.63^{* * *}$ & 1.15 \\
\hline Root glutamic acid & $19.29 * * *$ & $9.22^{* * *}$ & 0.12 & $4.34^{* *}$ & 1.7 & 0.46 & 0.3 \\
\hline Root asparagine & $17.03^{* * *}$ & $14.58^{* * *}$ & 0.28 & 1.91 & 3.84 & 2.24 & 1.99 \\
\hline Root aspartic acid & 32 & $7.86^{* * *}$ & 1.72 & $4.02^{* *}$ & 0.84 & $3.31^{*}$ & 2.19 \\
\hline Root threonine & 0 & $19.91^{* * *}$ & $93.19^{* * *}$ & $7.36^{* * *}$ & $13.08^{* * *}$ & $19.69^{* * *}$ & $2.46^{*}$ \\
\hline Root phenylalanine & $78.70^{* * *}$ & $90.43^{* * *}$ & $177.24^{* * *}$ & $96.78^{* * *}$ & $100.52^{* * *}$ & $98.98^{* * *}$ & $80.49 * * *$ \\
\hline Root lolines & $249.61^{* * *}$ & 0.73 & $36.01^{* * *}$ & 0.73 & $36.01^{* * *}$ & $3.14^{*}$ & $3.14^{*}$ \\
\hline
\end{tabular}

${ }^{1 * \prime}$ denotes $p$-values $=>0.01-0.05 ;{ }^{\text {***' }}$ denotes $p$-values $=>0.001-0.01 i^{{ }^{\prime * * * \prime}}$ denotes $p$-values $=<0.001$. 
Table 3 Three-factor ANOVA $\left[F_{\mathrm{df}}(5,48)\right]$ values of all metabolites in Experiment 3

\begin{tabular}{|c|c|c|c|c|c|c|c|}
\hline Metabolite & Endophyte & Day & Stress & Day * Endophyte & Stress * Endophyte & Stress * Day & Endophyte * Stress * Day \\
\hline Shoot glucose & 0.55 & $15.38 * * *$ & $188.58^{* * *}$ & 1.7 & 0.18 & $30.31^{* * *}$ & $2.67^{*}$ \\
\hline Shoot fructose & $5.01^{*}$ & $24.51^{* * *}$ & $344.35^{* * *}$ & 1.49 & 11.72 & $34.71^{* * *}$ & 1.56 \\
\hline Shoot sucrose & $4.78^{*}$ & $26.49^{* * *}$ & $97.38^{* * *}$ & 0.39 & $5.94^{*}$ & $17.83^{* * *}$ & $2.98^{*}$ \\
\hline Shoot GFS & 3.27 & $24.76^{* * *}$ & $320.43^{* * *}$ & 1.15 & $7.24^{* *}$ & $35.35^{* * *}$ & 2.01 \\
\hline Shoot proline & 0.5 & $37.81^{* * *}$ & $329.02^{* * *}$ & 0.87 & 0.6 & $38.41^{* * *}$ & 0.81 \\
\hline Shoot glutamine & 0.01 & $9.91 * * *$ & $117.18^{* * *}$ & 1.94 & 0.02 & $12.05^{* * *}$ & $2.62^{*}$ \\
\hline Shoot glutamic acid & 3.83 & $7.29^{* * *}$ & 0.66 & $3.64^{* *}$ & 1.97 & $6.94^{* * *}$ & $2.67^{*}$ \\
\hline Shoot asparagine & 0.82 & $8.43^{* * *}$ & $30.99^{* * *}$ & 0.41 & 0.12 & $3.87^{* *}$ & 1.13 \\
\hline Shoot aspartic acid & 0.76 & 1.17 & $33.33^{* * *}$ & 1.37 & 0.33 & $3.33^{*}$ & 0.52 \\
\hline Shoot tryptophan & $5.01^{*}$ & $24.51^{* * *}$ & $344.35^{* * *}$ & 1.49 & $11.72^{* *}$ & $34.71 * * *$ & 1.56 \\
\hline Shoot phenyl alanine & $4.78^{*}$ & $26.49^{* * *}$ & $97.38^{* * *}$ & 0.39 & $5.94^{*}$ & $17.83^{* * *}$ & $2.98^{*}$ \\
\hline Shoot tyrosine & 3.27 & $24.76^{* * *}$ & $320.43^{* * *}$ & 1.15 & $7.24^{* *}$ & $35.35^{* * *}$ & 2.01 \\
\hline Shoot threonine & 0.55 & $15.38^{* * *}$ & $188.58^{* * *}$ & 1.7 & 0.18 & $30.31^{* * *}$ & $2.67^{*}$ \\
\hline Shoot trehalose & $23.82^{* * *}$ & $10.87^{* * *}$ & $69.51^{* * *}$ & $2.83^{*}$ & $11.06^{* *}$ & $16.26^{* * *}$ & $5.79^{* * *}$ \\
\hline Shoot lolines & $507.88^{* * *}$ & 2.35 & $18.51^{* * *}$ & 2.35 & $18.51 * * *$ & 1.23 & 1.23 \\
\hline Root glucose & 0 & $3.41^{*}$ & 2.54 & 0.95 & 0.55 & $4.62^{* *}$ & 1.87 \\
\hline Root fructose & 2.2 & $8.00 * * *$ & $103.20^{* * *}$ & 0.93 & 1.56 & $14.24^{* * *}$ & $2.75^{*}$ \\
\hline Root sucrose & $4.23^{*}$ & $13.00^{* * *}$ & $32.14^{* * *}$ & 2.05 & 1.98 & $9.98^{* * *}$ & 1.27 \\
\hline Root GFS & 3.22 & $11.21^{* * *}$ & $72.15^{* * *}$ & 1.43 & 1.44 & $13.96 * *$ & $2.51^{*}$ \\
\hline Root proline & 0 & $9.55^{* * *}$ & $59.35^{* * *}$ & 1.93 & 0 & $8.94^{* * *}$ & 1.67 \\
\hline Root glutamine & 1.95 & $3.22^{*}$ & $24.14^{* * *}$ & 2.06 & 0.73 & 2.18 & 1.55 \\
\hline Root glutamic acid & 0.38 & $12.94^{* * *}$ & $6.74^{*}$ & 0.56 & 0.05 & 0.56 & 0.54 \\
\hline Root asparagine & 1.11 & 2.39 & $4.28^{*}$ & 1.21 & 1.61 & 0.4 & 1.53 \\
\hline Root aspartic acid & 0.17 & $32.52^{* * *}$ & $18.15^{* * *}$ & 0.47 & 0.08 & $3.75^{* *}$ & 0.34 \\
\hline Root tryptophan & 0.25 & $5.62^{* * *}$ & $56.82^{* * *}$ & 1 & 0.03 & $7.29^{* * *}$ & 0.46 \\
\hline Root phenylalanine & 0.31 & $5.38^{* * *}$ & $54.78^{* * *}$ & 1.13 & 0.03 & $7.01^{* * *}$ & 0.91 \\
\hline Root tyrosine & 0.42 & 1.35 & $13.37^{* * *}$ & 0.9 & 0.13 & $3.97^{* *}$ & 0.77 \\
\hline Root threonine & 2.07 & $7.32^{* * *}$ & $84.63^{* * *}$ & 1.13 & 2.75 & $9.03^{* * *}$ & 1.37 \\
\hline Root lolines & $455.13^{* * *}$ & $9.26^{* * *}$ & $19.28^{* * *}$ & $9.26^{* * *}$ & $19.28^{* * *}$ & 0.93 & 0.93 \\
\hline
\end{tabular}

${ }^{\prime * \prime}$ denotes $p$-values $=>0.01-0.05 ;{ }^{\prime * * \prime}$ denotes $p$-values $=>0.001-0.01 ;{ }^{i * * * \prime}$ denotes $p$-values $=<0.001$. 


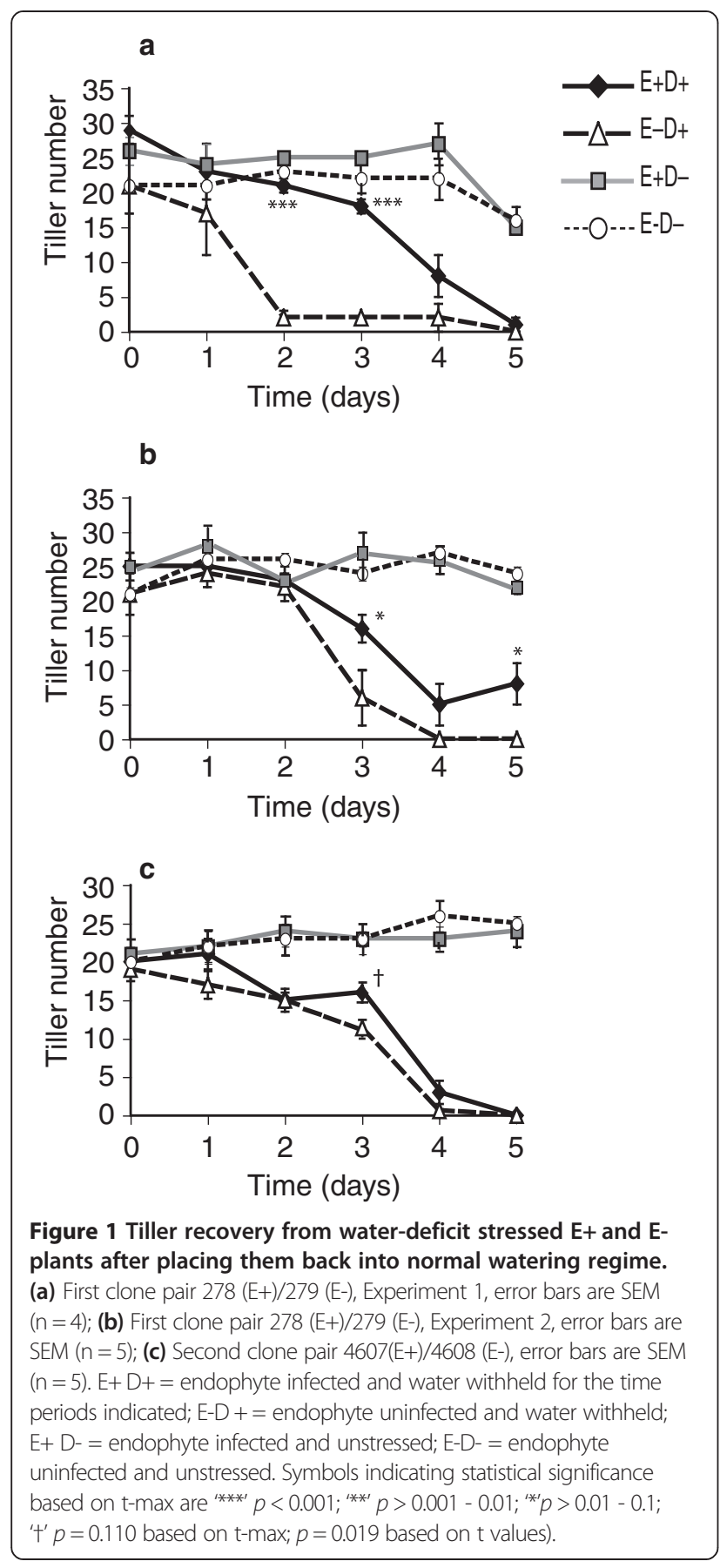

totals of glucose, fructose and sucrose at day $1, \mathrm{E}+$ clones had approximately 2-4 fold higher levels in shoots and roots compared to their watered controls, whereas the totals in E- clones did not differ significantly from their watered controls (see Additional file 2, panels a, b).

Results in Experiment 2, also with clone pair 278/279, were very similar except for a one-day delay in effects on tiller survival and metabolites, probably because of overcast skies on the first day (see Additional file 1, panel b). At day 2 of withholding water, free glucose and fructose levels in E+ were approximately 2-4 fold higher than in watered controls or in E-stressed plants (Figures 2c and 3c). There were no significant differences in sucrose levels at day 2 between $\mathrm{E}+$ and $\mathrm{E}$ plants (Figure 4c, Table 2). In roots, sucrose levels were 2-3 fold higher in E+ compared to E- roots from day 2 to day 4 (Figure $4 d$ ), though there were no significant differences in glucose or fructose (Figures $2 \mathrm{~d}$ and $3 \mathrm{~d}$, Table 2, and see Additional file 2, panels c, d).

Comparing free glucose and fructose sugars in clone pair $4607 / 4608$ during the water deficit period, there were significant differences between $\mathrm{E}+$ and $\mathrm{E}$ - in the roots (Figures $2 \mathrm{f}$ and $3 \mathrm{f}$ ); but not in shoots except for fructose at day 5, where E+ shoots accumulated fructose to higher levels than E- shoots (Figures 2e and $3 \mathrm{e}$ ). Root glucose and fructose concentrations increased by day 2 of withholding water, and were significantly higher in $\mathrm{E}+$ than $\mathrm{E}$ - plants.

The level of the disaccharide, trehalose, was low in the tall fescue clone pairs. However the trehalose levels were higher in water deficit tissues compared to the watered control samples (Tables 2 and 3), and after 3 days of withholding water significant higher levels of trehalose were observed in the E+clones compared to the Eclones (Figure $5 \mathrm{a}$ and $\mathrm{b}$ ).

\section{Sugar alcohols/polyols}

Levels of different sugar alcohols, including myo-inositol, mannitol, sorbitol, arabitol, galactinol, and chiro-inositol, were quantified in clone pair 278/279. Significant increases in myo-inositol were observed (days 2 and 3 ) in response to water deficit, but there was no significant effect of endophyte (Figure 6a, Table 2). Mannitol, a fungal metabolite, was undetectable in E-plants at most time points, but increased significantly in $\mathrm{E}+$ plants at day 3 after withholding water, compared to $\mathrm{E}+$ water controls (Figure 6b, Table 2). Sorbitol was found in both $\mathrm{E}+$ and E- plants, and water deficit and endophyte did not influence these levels significantly (Figure 6c, Table 2). Arabitol was not found in either E+ or Ewatered controls, but upon water deficit stress, arabitol accumulated with a maximum at day 3 in E+plants (Figure 6d, Table 2). Chiro-inositol levels were very low, and galactinol levels were not significantly affected by the endophyte or water deficit status (data not shown).

\section{Amino acids}

A total of 11 free amino acids were measured in watered controls and stressed shoot and root tissues of both clone pairs. The amino acids, methionine, arginine, ornithine and homoserine, were very low or undetectable. Levels of the amino acids valine, tryptophan, tyrosine, threonine, and phenylalanine were higher in stressed 

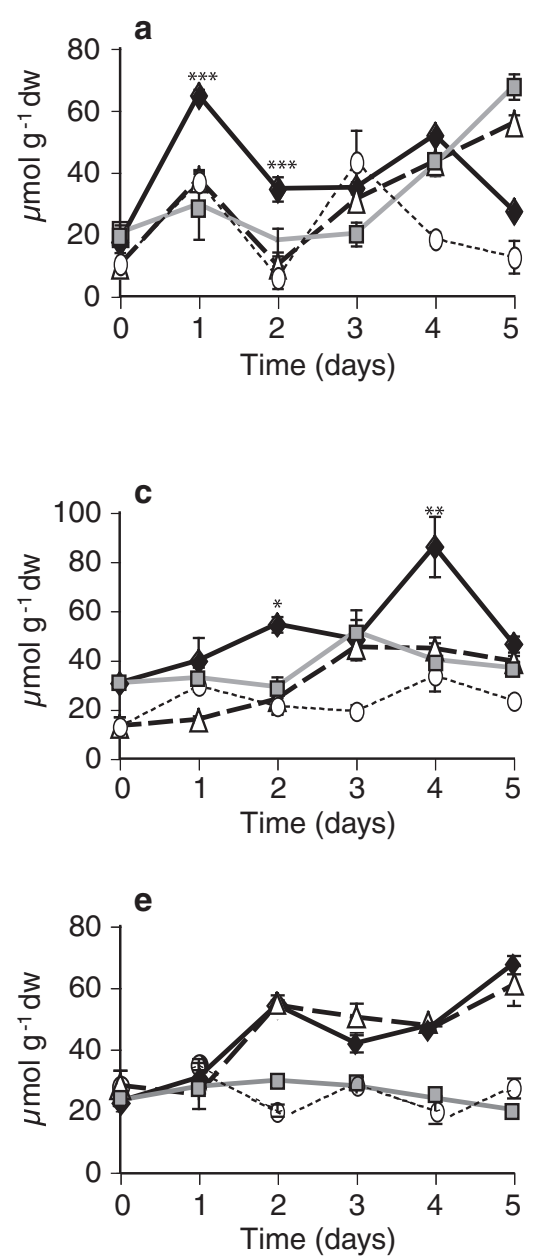

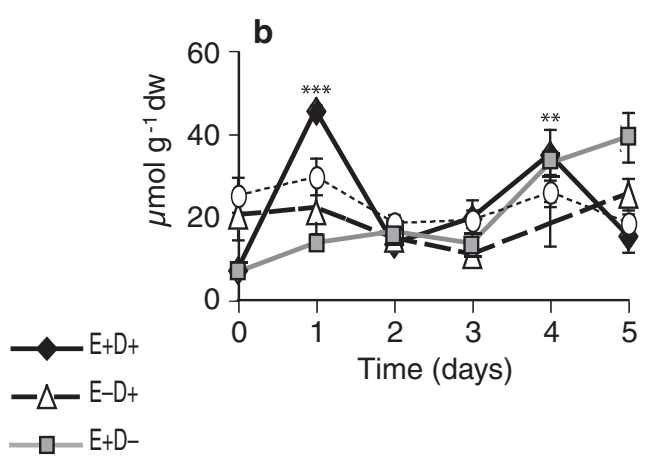

-.-O--.E-D-
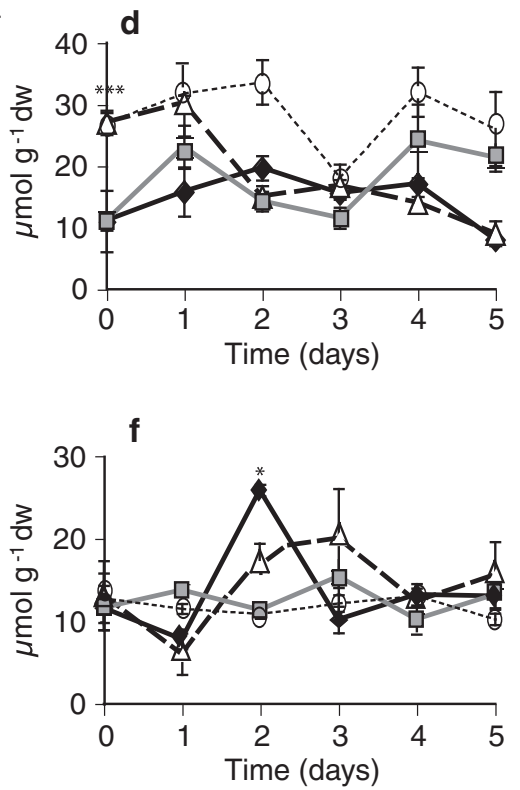

Figure 2 Comparison of glucose levels in water-deficit stressed and unstressed shoots and roots of tall fescue. (a and $\mathbf{b})$ Shoots and roots, respectively, of the 278/279 clone pair, Experiment 1, error bars are SEM $(n=4)$; $(\mathbf{c}$ and $\mathbf{d})$ shoots and roots, respectively, of the 278/279 clone pair, Experiment 2, error bars are SEM $(n=3)$; $(\mathbf{e}$ and $\mathbf{f})$ shoots and roots, respectively, of the 4607/4608 clone pair, error bars are SEM $(n=3)$. $E+D+=$ endophyte infected and water withheld for the time periods indicated; $E-D+=$ endophyte uninfected and water withheld; E+D- = endophyte infected and unstressed; E-D- = endophyte uninfected and unstressed. Statistical significance is indicated as in Figure 1.

plants from day 2 to day 5 compared to watered controls, but no consistent endophyte effects on these amino-acid levels were observed (Tables 1, 2 and 3). Serine levels did not change due to endophyte or water deficit stress. In the first experiment with the 278/279 clone pair, proline levels in shoots and roots of E+ and E- clones increased under water deficit stress, but not in watered controls (Figure $7 \mathrm{a}$ and b, Table 1). At day 1 of withholding water, levels of proline increased approximately 6-fold in E+ shoots and roots, whereas comparable increases in E- plants were not observed till day 2 . Thus, levels of proline at day 1 were significantly greater in $\mathrm{E}+$ than in E-plants (Figure $7 \mathrm{a}$ and $\mathrm{b}$ ). On day 2 of water deficit, and thereafter, there were no significant differences in the levels of proline between E+and E- plants until day 4. However, levels in the treated clones remained approximately 13-15-fold higher than in watered controls. In this experiment, the elevated levels of proline were accompanied by a slight decrease in glutamine levels (data not shown), but the total levels of proline, glutamine, and glutamic acid, which are metabolically interrelated, were higher in the stressed tissues. There were no significant differences in asparagine levels between $\mathrm{E}+$ and $\mathrm{E}$ - plants upon water deficit (Table 1).

In the second experiment with clone pair 278/279, increases in amino acid levels started from day 3 after withholding water. At that time point, proline levels in E+ clones were significantly higher than in E- clones both in shoots (Figure 7c) and roots (Figure 7d).

In the experiment with clone pair 4607/4608, proline levels increased in shoots of both E+ and E- plants by day 2 of withholding water, but endophyte effect was not significant (Figure 7e, Table 3). However, levels 

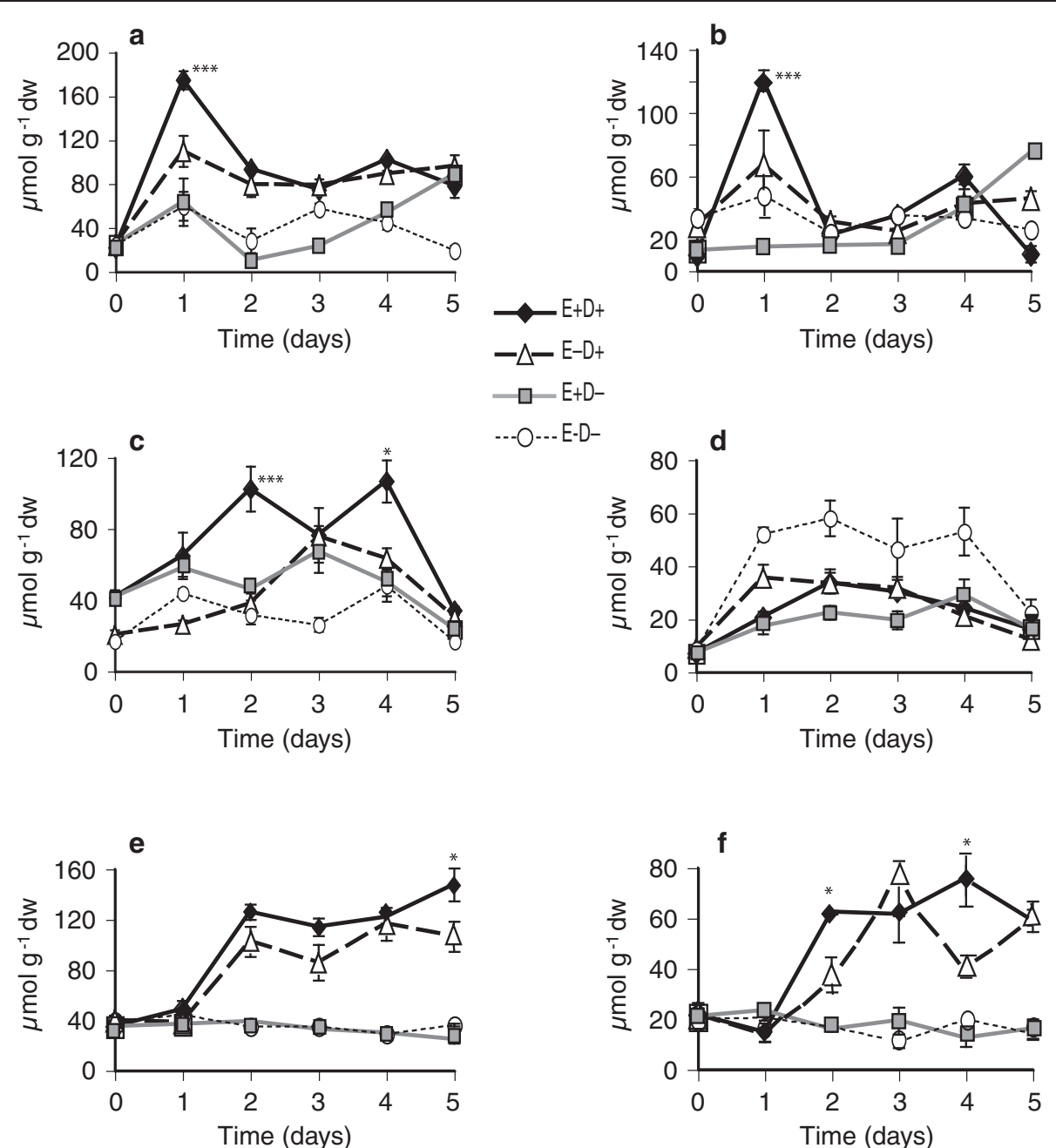

Figure 3 Fructose levels in water-deficit stressed and unstressed shoots ( $a, c$, and e) and roots (b, d, and f) of tall fescue. (a and b) Shoots and roots, respectively, of 278/279 clone pair, Experiment 1; (c and d) shoots and roots, respectively, of 278/279 clone pair, Experiment 2; (e and $\mathbf{f}$ ) shoots and roots, respectively, of 4607/4608 clone pair. Abbreviations are as in Figure 2. Statistical significance is indicated as in Figure 1. Error bars are SEM of biological replicates as indicated in Figure 2.

of glutamine and glutamic acid, which are metabolically linked to proline, were higher at day 2 after water deficit (Figure $8 \mathrm{a}$ and $\mathrm{c}$ ); and glutamic acid was significantly higher in E+compared to E- shoots (Figure 8c). Similarly, in stressed roots, proline levels did not significantly differ between E+ and E- (Figure 7f, Table 3), but at day 2 glutamine reached approximately 3 -fold higher levels in E+ roots compared to E- stressed roots and to watered controls (Figure 8b). Asparagine levels increased in shoots by day 2 of withholding water, but were not significantly different between E+and E- shoots (Figure 8e, Table 3). However, in roots, asparagine levels were significantly higher at day 2 in $\mathrm{E}+$ compared to E- clones (Figure 8f). Overall, in this genotype, the endophyte effects on metabolites were evident especially in roots within two days of withholding water.

\section{Loline alkaloids}

Lolines are the most abundant alkaloids produced by $N$. coenophialum in tall fescue, where the major forms are $N$ formylloline and $N$-acetylloline, although $N$-methylloline and $N$-acetylnorloline are also detected. In Experiment 1 with clone pair 278/279, total loline alkaloid levels in E+ shoot samples were higher in stressed clones from day 2 to day 4 of withholding water (Figure 9a, Table 1). Lower amounts of lolines were detected in root samples compared to shoot samples (Figure 9b). As expected, lolines were undetectable in E- root and shoot samples. In the second experiment with same clone pair, lolines increased in stressed shoots and were significantly different from watered controls by day 3 (Figure 9c and d, Table 2). Loline levels in clone pair 4607/4608 showed similar trends (Figure 9e and f, Table 3). 

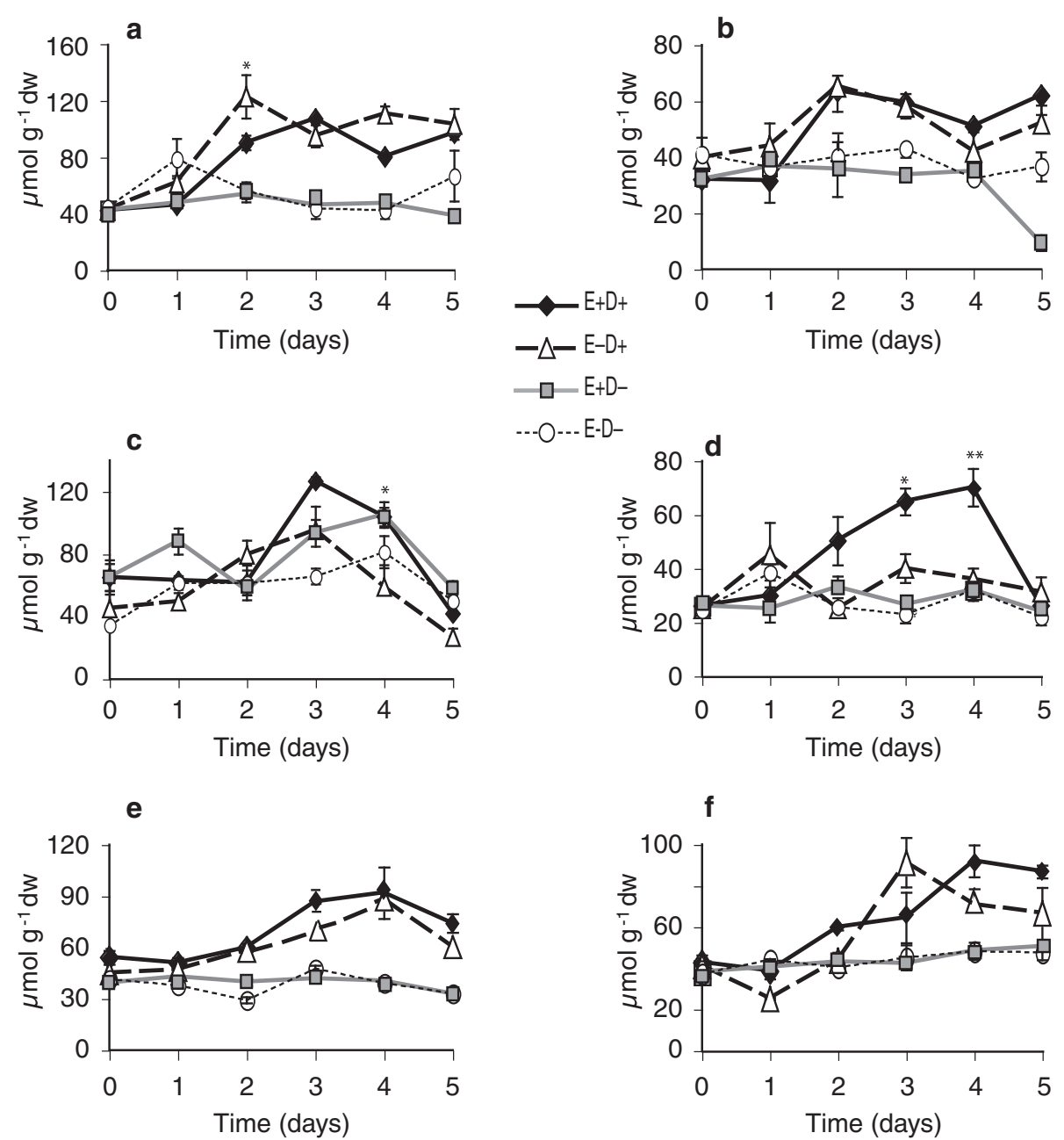

Figure 4 Sucrose levels in water-deficit stressed and unstressed shoots and roots of tall fescue. (a and $\mathbf{b})$ Shoots and roots, respectively, of 278/279 clone pair, Experiment 1; (c and $\mathbf{d}$ ) shoots and roots, respectively, of 278/279 clone pair, Experiment 2; (e and f) shoots and roots, respectively, of $4607 / 4608$ clone pair. Abbreviations are as in Figure 2. Statistical significance is indicated as in Figure 1. Error bars are SEM of biological replicates as indicated in Figure 2 .

\section{Discussion}

We assessed plant survival and differences in metabolite accumulation in two tall fescue clone pairs with $(\mathrm{E}+)$ or without (E-) symbiotic Neotyphodium coenophialum over a time course of water deficit stress, and observed that E+ plants recovered significantly better than E- plants after 2-3 days of withholding water. Simultaneously, the E+ plants consistently accumulated more free sugars, sugar alcohols and amino acids early during the onset of stress, compared to E- plants. The fungal-specific metabolites, mannitol and loline alkaloids, also increased in this time period. The higher metabolite levels in E+ compared to E- plants over the time course of withholding water consistently occurred within one day prior to a significant endophyte effect on plant recovery, strongly suggesting that free sugars, polyols, amino acids, and fungal metabolites play roles in endophyte-enhanced tolerance to water deficit. The production or release of these substances may lead to osmotic adjustment [20,36], and help maintain integrity of cellular enzymes, proteins, nucleic acids and membranes [37], or protect against reactive oxygen species (ROS) [38,39].

The accumulation of soluble sugars is strongly correlated with drought tolerance in plants [40]. These sugars affect osmotic adjustment, which is considered an important mechanism to allow maintenance of water uptake and cell turgor under stress conditions [41]. Furthermore, hydroxyl groups of sugars and polyols can interact with proteins and membranes to prevent denaturation and help avoid the crystallization of cytoplasm under low-water stress $[42,43]$. In addition, these sugars have been shown to be important regulatory molecules in different signaling pathways [22,44], helping to maintain redox balance, and acting as reactive oxygen scavengers [45,46]. In general, 


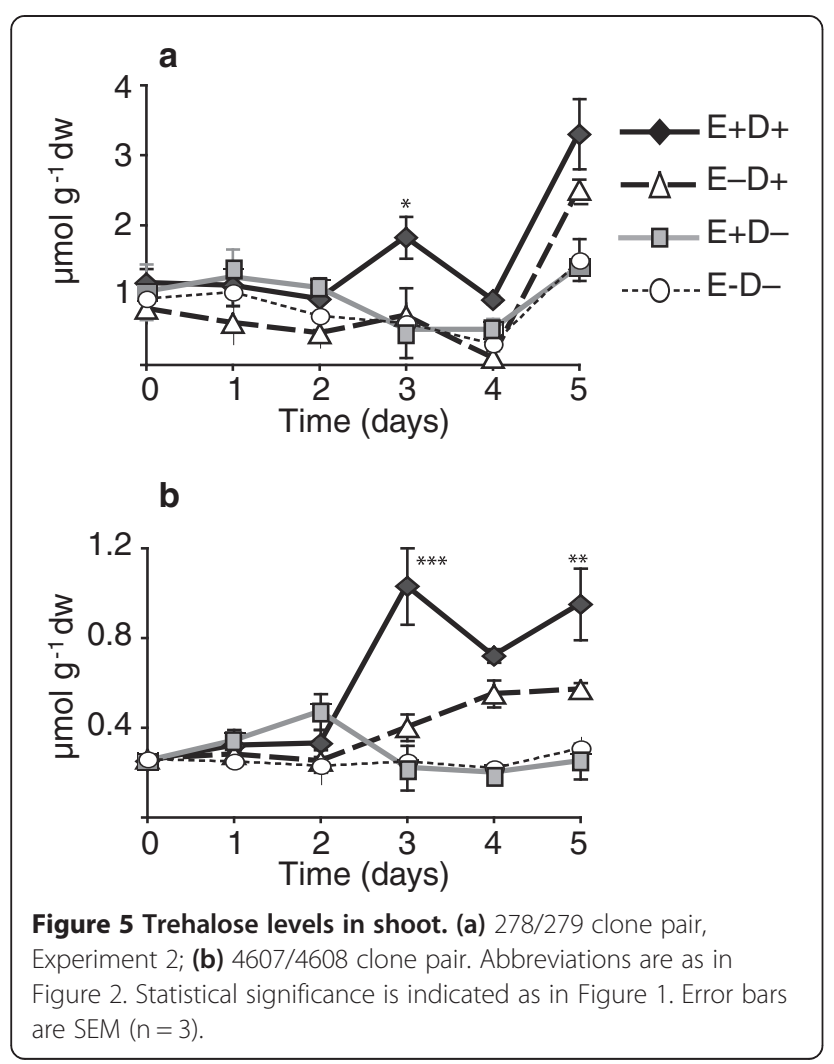

endophytic fungi are similar to plant pathogenic fungi in possessing glucan hydrolase-32 (GH32 invertase) enzymes that convert sucrose into glucose and fructose for catabolism [47]. Fungal invertase activity and presence of invertase gene transcripts have been reported in some of the grass endophytes $[48,49]$, so under the conditions imposed in our study, fungal enzymes may play at least a partial role in the observed increases in these free sugars.

Mannitol and arabitol are common polyols in fungi, and have been observed to accumulate in plants during infection [50]. We found that both polyols increased in response to water deficit in the E+tall fescue clones. Our results, are in agreement with Richardson et al. [26] who reported mannitol in E+ tall fescue plants, although they did not see an effect on the mannitol levels when the plants were osmotically stressed with polyethylene glycol. Arabitol accumulated essentially only under stress (Figure 6) conditions [26]. Most plants do not normally contain mannitol, with some salt tolerant species, such as celery, as exceptions [51]. Note that the very low levels of mannitol in some E- plants was likely due to the presence of commensal fungi on the plants, since the plants were not grown axenically. Plants engineered to produce mannitol have shown increased tolerances to drought, salt, and temperature stresses [52-55], so mannitol in the E+ plants may have contributed to their tolerance of water deficit stress.
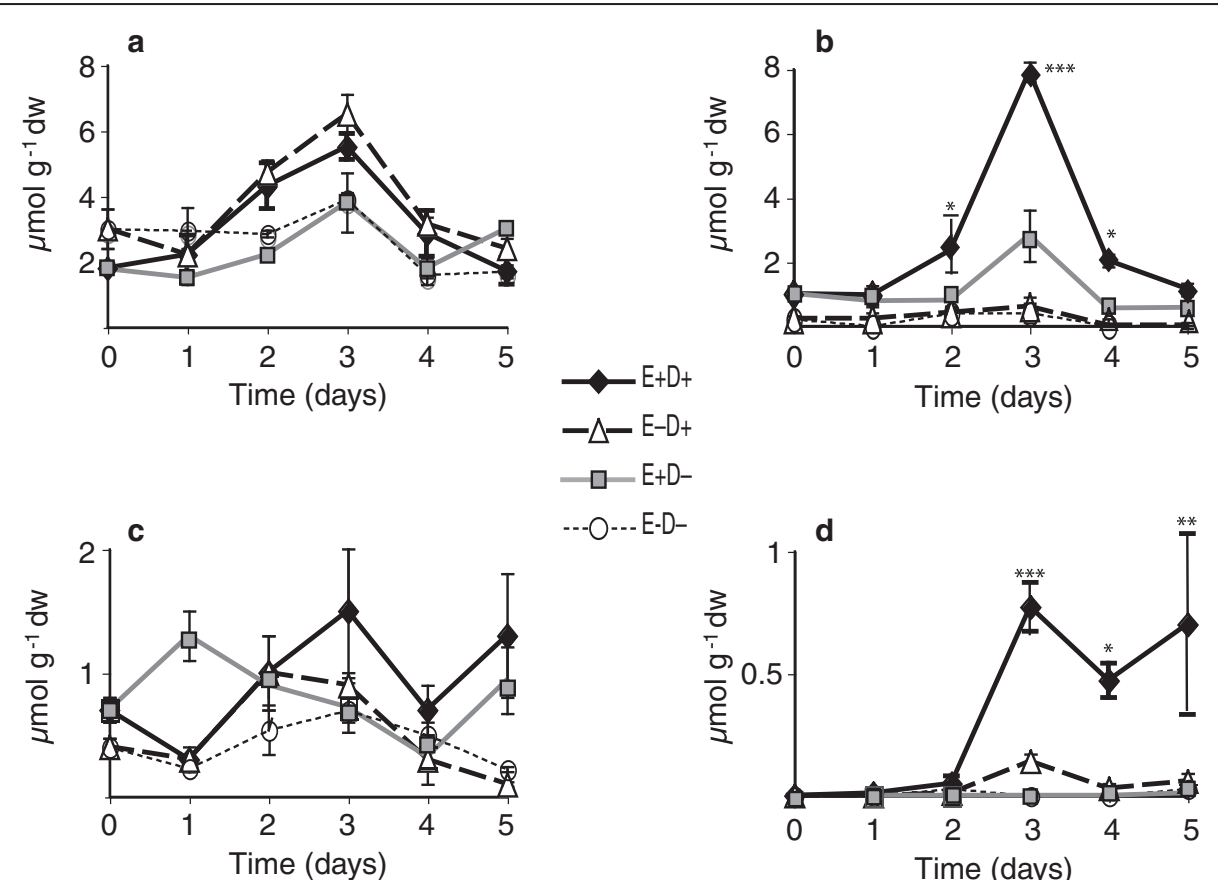

--.O--.E-D-

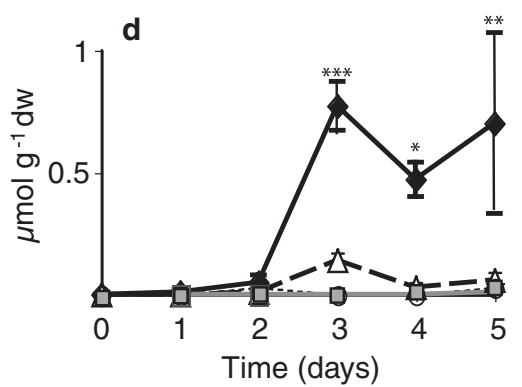

Figure 6 Sugar alcohols or polyols in water-deficit stressed and unstressed shoots of tall fescue. Shown are, (a) myo-inositol, (b) mannitol, (c) sorbitol, (d) and arabitol in the shoots of unstressed and water-deficit stressed plants in Experiment 2 with the 278/279 clone pair. Statistical significance is indicated as in Figure 1. Error bars are SEM $(n=3)$. 

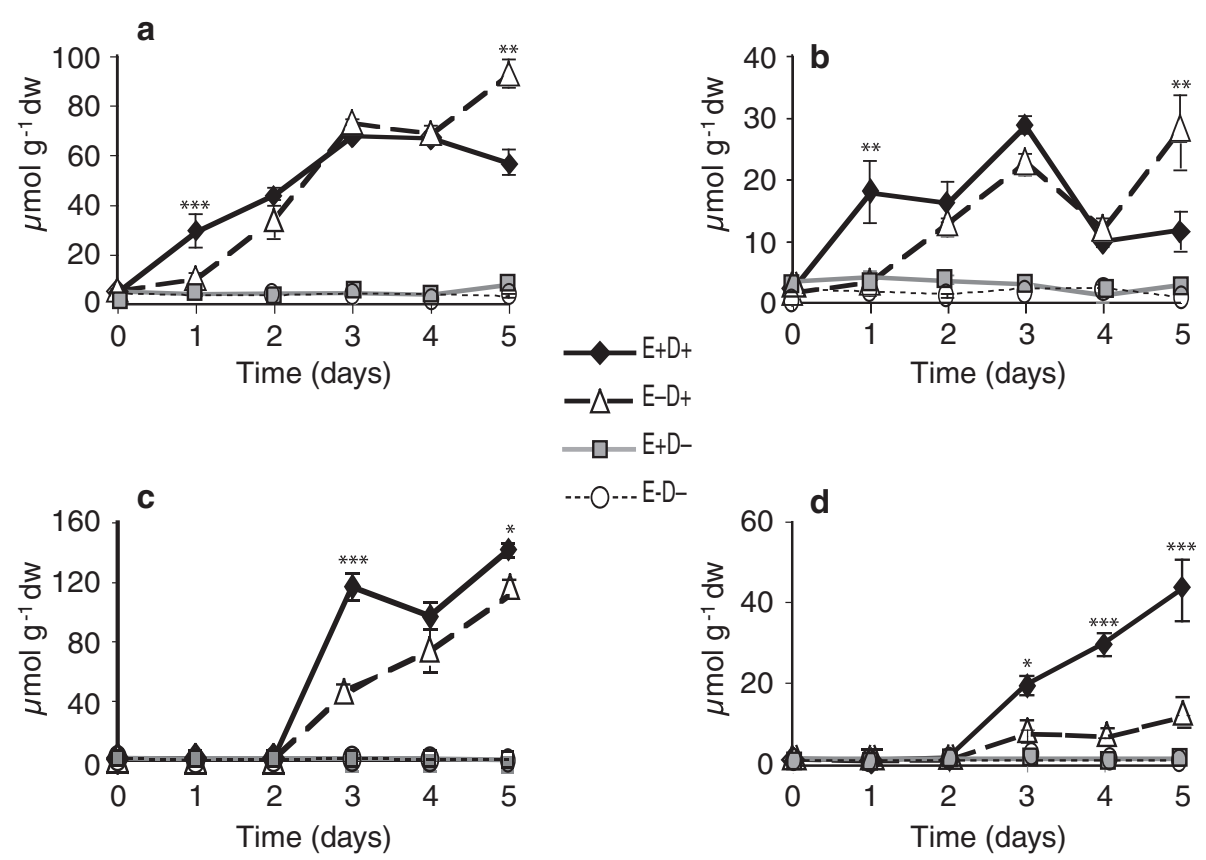

-.-O-.-E-D-
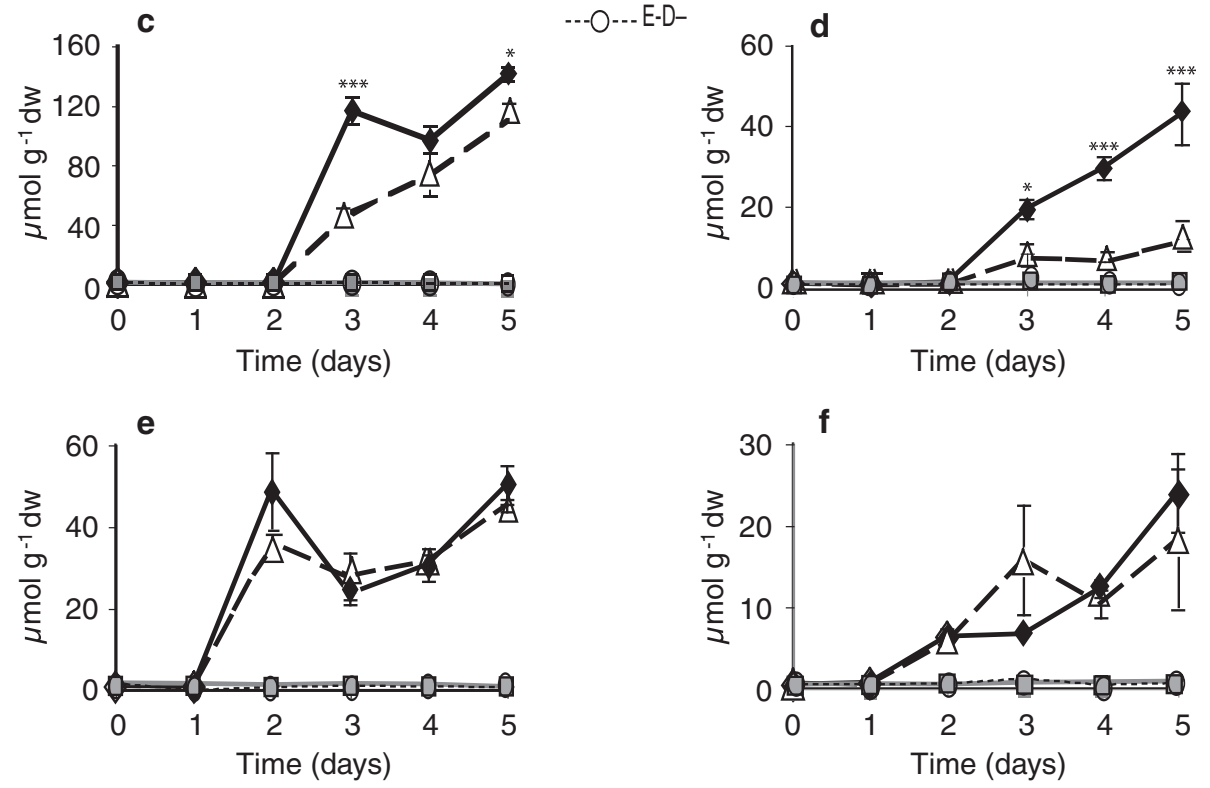

Figure 7 Proline levels in water-deficit stressed and unstressed shoots and roots of tall fescue. (a and $\mathbf{b})$ Shoots and roots, respectively, of 278/279 clone pair, Experiment 1; (c and $\mathbf{d})$ shoots and roots, respectively, of 278/279 clone pair, Experiment 2; (e and f) shoots and roots, respectively, of $4607 / 4608$ clone pair. Abbreviations are as in Figure 2. Statistical significance is indicated as in Figure 1. Error bars are SEM of biological replicates as indicated in Figure 2.

The non-reducing disaccharide, trehalose, is an important osmoprotectant and storage carbohydrate in many organisms. In plants, the trehalose pathway is ubiquitous and indispensible, but with a few exceptions, such as in resurrection plants, trehalose typically does not accumulate to high levels, possibly due to trehalase-catalyzed cleavage to glucose. Significant increases in trehalose accumulation have been accomplished thorough transgenic approaches, and shown to protect plants from drought and salt stresses [56-59]. However, the overproduction or accumulation of high levels of trehalose is also observed to cause growth aberrations in some of the transgenic experiments [60-63]. In our studies, we observed increased levels of trehalose after 3 days of withholding water, with significantly higher levels in E+plants. Although the overall levels of trehalose observed in the E+ and E- plants were very low compared to the other soluble sugars and polyols, the observed spike in trehalose accumulation during stress, and differences between $\mathrm{E}+$ and $\mathrm{E}$ - plants in trehalose levels suggest a possible functional role. While it is possible that the low trehalose levels observed in these plants could function in stress tolerance [64], it seems more likely that the trehalose accumulation is associated with the signaling/regulation role that has been documented [65-70].

Water deficit has been shown to increase levels of ROS, so an important role of accumulated metabolites appears to be scavenging or detoxifying ROS $[45,71,72]$. Production of phenolics, carbohydrates, mannitol, and proline with antioxidant capacity protects plants from oxidative stress under water-deficit conditions. As reviewed by White and Torres [73], symbiotic plants are protected from different abiotic and biotic stresses by production of these antioxidants. 

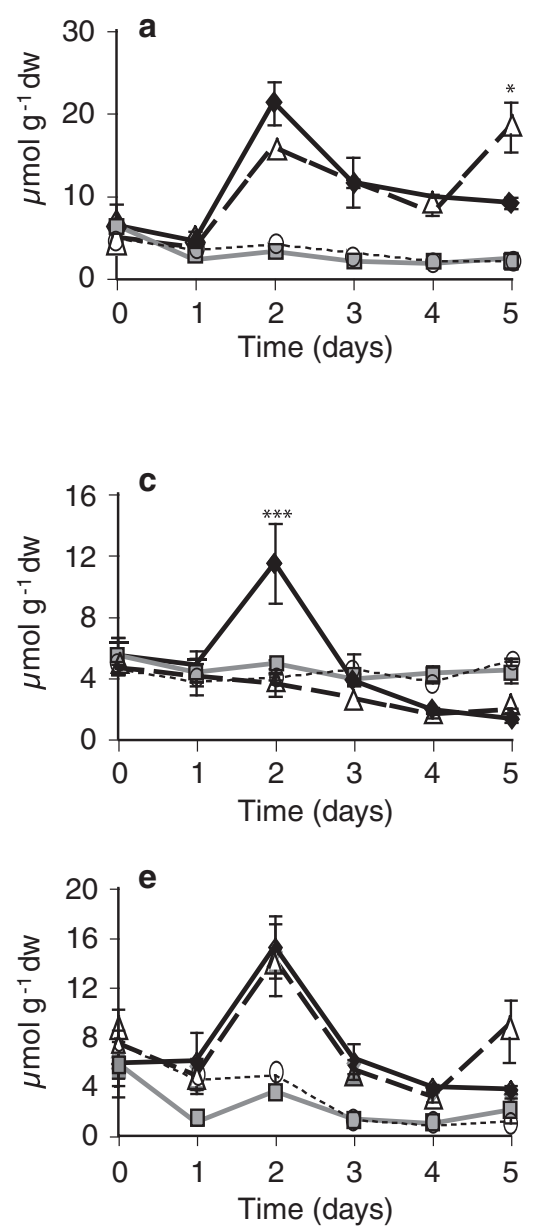

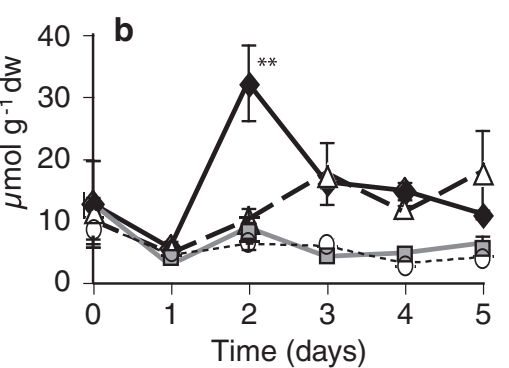

$-\Delta-E-D+$
$-\square-E+D-$
$\cdots-.-E-D-$
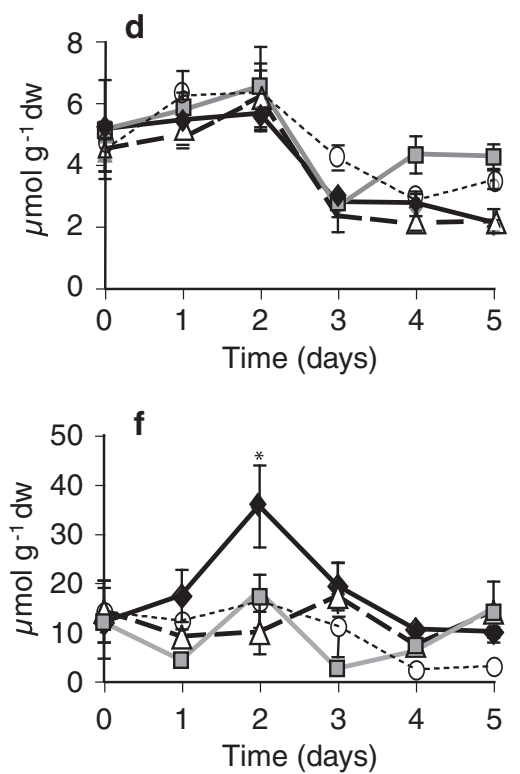

Figure 8 Some of the metabolite levels in 4607/4608 clone pair shoots of water-deficit stressed and unstressed plants. (a) glutamine in the shoot (b) glutamine in the root (c) glutamic acid in the shoot (d) glutamic acid in the root (e) asparagine in the shoot (f) asparagine in the root. Abbreviations are as in Figure 2. Statistical significance is indicated as in Figure 1. Error bars are SEM $(n=3)$.

The timing of metabolite changes was also highly suggestive of their roles in endophyte-enhanced stress tolerance. In all three experiments we observed endophyteenhanced increases in certain sugars, sugar alcohols and amino acids one day before observing the significant endophyte effect on recovery of the stressed plants. Interestingly, endophyte effects on levels of most metabolites were brief, since levels of these metabolites in E+ plants decreased or plateaued over the following days to levels similar to those in E- plants. In addition to enhancing osmotic adjustment, it is also possible that these accumulated solutes provided energy, carbon and nitrogen for the survival of meristematic regions, and helped in regrowth of the plant after the water deficit was alleviated.

Levels of several amino acids have been shown to increase in drought stressed plants [74]. In our experiments, the levels of proline, threonine, tryptophan, phenylalanine, tyrosine, and valine increased upon water deficit stress. In addition, proline was found to be consistently higher in both shoots and roots of E+ stressed plants than in E- stressed plants. A correlation between free proline accumulation and the performance of crops in the field at low water availability suggests that its accumulation is a drought stress adaptive response that enhances survival [75]. Proline may serve as an osmoregulator [74] and also as a ROS scavenger [76].

Loline alkaloids are protective secondary metabolites produced by the endophyte in tall fescue and other cool season grasses $[77,78]$. We observed increased loline alkaloid levels in response to water deficit stress in both clone pairs. Lolines are derived from proline and aspartate [79]. Conceivably, proline is depleted by loline production [80], but since no differences in proline levels were observed between $\mathrm{E}+$ and E- plants in unstressed conditions, proline levels were apparently adjusted in response to loline alkaloid synthesis. In the first experiment with clone pair 278/ 279 total proline and loline levels in E+ plants were higher even at day 2 after withholding water compared to Eplants, though levels of proline (and the metabolically closely related amino acids, glutamic acid and glutamine) 


\section{a}

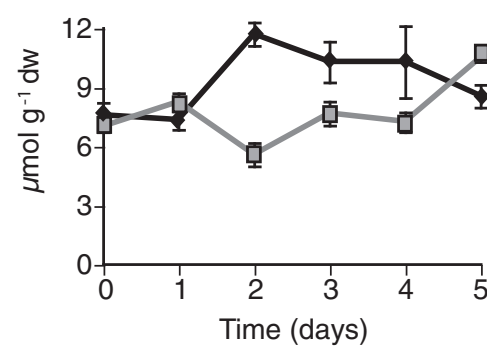

C

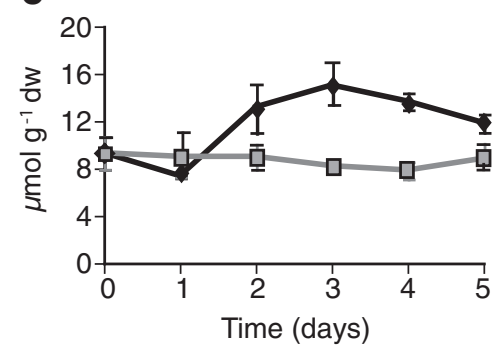

e

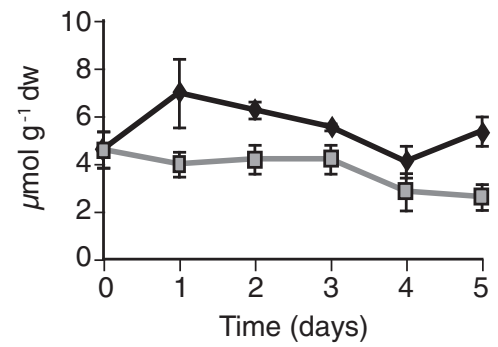

b

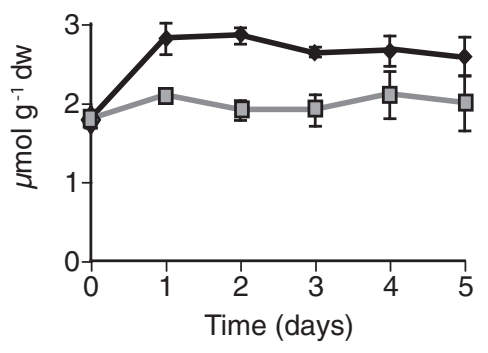

- $-E+D-$

d

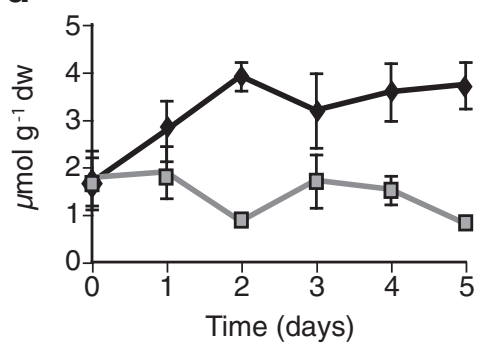

f

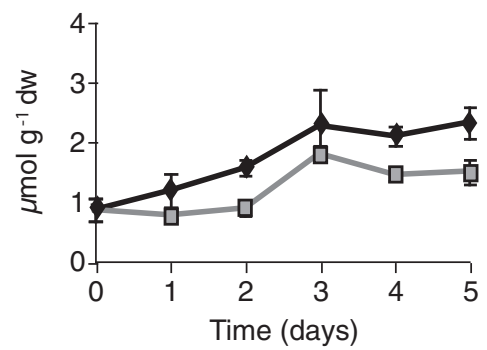

Figure 9 Loline levels in water-deficit stressed and unstressed shoots and roots of tall fescue. (a and $\mathbf{b})$ Shoots and roots, respectively, of 278/279 clone pair, Experiment 1; (c and d) shoots and roots, respectively, of 278/279 clone pair, Experiment 2; (e and f) shoots and roots, respectively, of $4607 / 4608$ clone pair. Abbreviations are as in Figure 2. Statistical significance is indicated as in Figure 1. Error bars are SEM of biological replicates as indicated in Figure 2.

were not different in between E+ and E- plants at day 2. It is possible that the proline is converted to loline in the $\mathrm{E}+$ plants, thus maintaining an apparent equal proline level as that of E- plants. However, in the other two experiments, the levels of proline in stressed tissues were far higher compared to amounts of lolines that accumulated in those tissues. Although water deficit has been reported to increase loline alkaloid levels in leaf tissues of some tall fescue accessions [81], a direct role of loline alkaloids on water stress tolerance has not yet been demonstrated.

Differences in the timing of metabolite accumulation were observed between two experiments with the same clone pair (278/279), with metabolite peaks at day 1 in Experiment 1 and the corresponding peaks occurring at day 2 or 3 in Experiment 2. This difference may be because of weather and greenhouse conditions that differed between these experiments. Specifically, day 1 of Experiment 2 was accompanied with thunderstorms and heavily overcast skies, resulting in lower photoactive radiation compared to day 1 of Experiment 1 (see Additional file 1, panel b), apparently delaying the onset of drought stress as evidenced by the tiller recovery curves (see Figure 1a and b). Similarly the observed metabolite differences between the experiments with different clone pairs could be due to plant genotype effects. Nevertheless, it was clear that, in our experiments the endophyte in tall fescue sped up plant responses to water deficit by earlier and faster accumulation of metabolites compared to uninfected tall fescue plants. Similar results have been reported in bacterial endophyte-plant systems. Bacterial endophyte enhances cold tolerance of grapevine plants by altering sugar metabolism and photosynthesis [82], and with higher and faster accumulation of stress related gene transcripts and metabolites [83]. 
Rasmussen et al. [84] have conducted comprehensive metabolomic studies in the related grass, Lolium perenne (perennial ryegrass), and have shown significant effects of the endophyte, Neotyphodium lolii, on primary and secondary metabolism of that grass. The need for more research to identify robust metabolic traits and pathways relating to drought tolerance in forage grasses through integration of metabolomic and transcriptomic data have been emphasized in reviews [85]. From our study it was evident that endophyte can affect tall fescue plant metabolism, in response to water deficit stress. Analyzing these endophyte effects on host plants at the molecular genetic level by transcriptome profiling is another approach, that we will be exploring further to help elucidate the mechanisms of endophyte-enhanced plant growth and survival under water deficit conditions.

\section{Conclusions}

In conclusion, enabling the plant cells to sense and respond quickly to surrounding environmental signals or stresses is important for their metabolic and developmental adjustments, and these responses may be enhanced due either to primary or secondary metabolite signals $[86,87]$. As we observed in the tall fescue clone pairs, symbiotic fungi in the infected plants may have induced, or rapidly activated, the plant biochemical reactions to accumulate the metabolites early in stress conditions, and this may be one of the ways that the presence of the endophyte helps mitigate the effects of, and enhance recovery from, water deficit stress. The results presented here demonstrate that symbiosis with endophytes can significantly enhance recovery of host plants from water deficit stress, and the effect corresponds in timing with accumulation of organic solutes that may serve as osmolytes and cellular protectants in leaves and roots.

\section{Additional files}

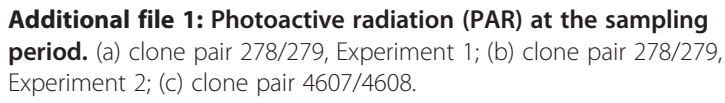

Additional file 2: Total amounts of glucose, fructose, sucrose (GFS) in water-deficit stressed and unstressed plants of tall fescue clone pairs. ( $a$ and b) Shoots and roots, respectively, of clone pair 278/279, Experiment 1; (c and d) shoots and roots, respectively, of clone pair 278/279, Experiment 2; (e and f) shoots and roots, respectively, of clone pair 4607/4608.

\section{Competing interests}

The authors declare that they have no competing interests.

\section{Authors' contributions}

PN designed and performed all experiments, and drafted the manuscript. RDD helped design experiments, generated and provided clone pair 4607/ 4608 , and helped draft the manuscript. CLW performed statistical analyses. CWB generated and provided clone pair 278/279, and helped draft the manuscript. CLS devised and supervised experiments and helped draft the manuscript. All authors read and approved the final manuscript.

\section{Acknowledgements}

This research is funded by USDA-ARS Specific Cooperative Agreement 200911131030. The authors are grateful for help and suggestions from Dr. Bruce A. Downie in HPLC for carbohydrates. The authors also thank J. Douglas Brown and W. Troy Bass for maintaining plants, and Dr. Lowell P. Bush and Dr. Fanniel F. Fannin for providing the loline alkaloid standard. The authors also acknowledge the ERTL facility at the University of Kentucky for allowing use of the LCMS and for technical assistance. This is publication number 13-12-101 of the Kentucky Agricultural Experiment Station, published with approval of the director.

\section{Author details}

'Department of Plant Pathology, University of Kentucky, Lexington, KY 40546-0312, USA. ²USDA-ARS, Forage-Animal Production Research Unit Lexington, KY 40546-0091, USA. ${ }^{3}$ Department of Statistics, University of Kentucky, Lexington, KY 40506-0027, USA. ${ }^{4}$ USDA-ARS, Toxicology and Mycotoxin Research Unit, Athens, GA 30605-2720, USA.

Received: 19 February 2013 Accepted: 1 August 2013

Published: 9 September 2013

\section{References}

1. Fribourg HA, Hannaway DB, West CP: Tall fescue for the twenty-first Century. ASA, CSSA, SSSA: Madison, Wl; 2010

2. Schardl CL, Leuchtmann A, Spiering MJ: Symbioses of grasses with seedborne fungal endophytes. Annu Rev Plant Biol 2004, 55:315-340.

3. Arachevaleta M, Bacon CW, Hoveland CS, Radcliffe DE: Effect of the tall fescue endophyte on plant response to environmental stress. Agron J 1989, 81:83-90.

4. West CP: Physiology and drought tolerance of endophyte-infected grasses. In Biotechnology of Endophytic Fungi of Grasses. Edited by Bacon CW, White JF. Boca Raton, FL: CRC Press; 1994:87-99.

5. West $C P$, Izekor E, Turner KE, Elmi AA: Endophyte effects on growth and persistence of tall fescue along a water-supply gradient. Agron J 1993, 85:264-270

6. Bacon CW: Abiotic stress tolerances (moisture, nutrients) and photosynthesis in endophyte-infected tall fescue. Agric Ecosyst Environ 1993, 44:123-141.

7. Malinowski DP, Belesky DP: Adaptations of endophyte-infected cool-season grasses to environmental stresses: Mechanisms of drought and mineral stress tolerance. Crop Sci 2000, 40:923-940.

8. Zhang $Y$, Nan ZB: Growth and anti-oxidative systems changes in Elymus dahuricus is affected by Neotyphodium endophyte under contrasting water availability. J Agron Crop Sci 2007, 193:377-386.

9. Hahn H, McManus MT, Warnstorff K, Monahan BJ, Young CA, Davies E, Tapper BA, Scott B: Neotyphodium fungal endophytes confer physiological protection to perennial ryegrass (Lolium perenne L.) subjected to a water deficit. Environ Exper Bot 2008, 63:183-199.

10. White RH, Engelke MC, Morton SJ, Johnsoncicalese JM, Ruemmele BA: Acremonium endophyte effects on tall fescue drought tolerance. Crop Sci 1992, 32:1392-1396.

11. Carrow RN: Drought avoidance characteristics of diverse tall fescue cultivars. Crop Sci 1996, 36:371-377.

12. Bayat F, Mirlohi A, Khodambashi M: Effects of endophytic fungi on some drought tolerance mechanisms of tall fescue in a hydroponics culture. Russ J Plant Physiol 2009, 56:510-516.

13. Hill NS, Pachon JG, Bacon CW: Acremonium coenophialum-mediated short- and long-term drought acclimation in tall fescue. Crop Sci 1996, 36:665-672.

14. Richardson MD, Hoveland CS, Bacon CW: Photosynthesis and stomatal conductance of symbiotic and nonsymbiotic tall fescue. Crop Sci 1993 33:145-149.

15. Malinowski DP, Alloush GA, Belesky DP: Evidence for chemical changes on the root surface of tall fescue in response to infection with the fungal endophyte Neotyphodium coenophialum. Plant Soil 1998, 205:1-12.

16. Swarthout D, Harper E, Judd S, Gonthier D, Shyne R, Stowe T, Bultman T: Measures of leaf-level water-use efficiency in drought stressed 
endophyte infected and non-infected tall fescue grasses. Environ Exper Bot 2009, 66:88-93.

17. Joost RE, Holder TL: Effect of endophyte infection on ABA content and drought response of tall fescue. In Agronomy Abstracts. Madison, Wl: American Society of Agronomy; 1994:140.

18. Buck GW, West CP, Elbersen HW: Endophyte effect on drought tolerance in diverse Festuca species. In Neotyphodium-Grass Interactions. Edited by Bacon CW, Hill NS. New York, NY: Plenum Press; 1997:141-143.

19. Elmi AA, West CP: Endophyte Infection effects on stomatal conductance, osmotic adjustment and drought recovery of tall fescue. New Phytol 1995, 131:61-67

20. Chen H, Jiang JG: Osmotic adjustment and plant adaptation to environmental changes related to drought and salinity. Environ Rev 2010, 18:309-319.

21. Spollen WG, Nelson CJ: Response of fructan to water deficit in growing leaves of tall fescue. Plant Physiol 1994, 106:329-336

22. Hanson J, Smeekens S: Sugar perception and signaling - an update. Curr Opin Plant Biol 2009, 12:562-567.

23. Loescher WH: Physiology and metabolism of sugar alcohols in higher-plants. Physiol Plant 1987, 70:553-557.

24. Abernethy GA, McManus MT: Biochemical responses to an imposed water deficit in mature leaf tissue of Festuca arundinacea. Environ Exper Bot 1998, 40:17-28.

25. Bandurska $\mathrm{H}$, Jóźwiak W: A comparison of the effects of drought on proline accumulation and peroxidases activity in leaves of Festuca rubra L. and Lolium perenne L. Acta Soc Bot Pol 2010, 79:111-116.

26. Richardson MD, Chapman GW, Hoveland CS, Bacon CW: Sugar alcohols in endophyte-infected tall fescue under drought. Crop Sci 1992, 32:1060-1061.

27. Assuero SG, Tognetti JA, Colabelli MR, Agnusdei MG, Petroni EC, Posse MA: Endophyte infection accelerates morpho-physiological responses to water deficit in tall fescue. N Z J Agri Res 2006, 49:359-370

28. Man $D$, Bao $Y X$, Han $L B$, Zhang $X Z$ : Drought tolerance associated with proline and hormone metabolism in two tall fescue cultivars. Hortscience 2011, 46:1027-1032.

29. de Battista J, Bouto J, Bacon C, Siegel M: Rhizome and herbage production of endophyte-removed tall fescue clones and populations. Agron J 1990, 82:651-654

30. Bacon C, White J: Stains, media and procedures for analyzing endophytes. In Biotechnology of Endophytic Fungi of Grasses. Edited by Bacon CW, White J. Boca Raton, FL: CRC Press; 1994:47-56.

31. An ZQ, Siegel MR, Hollin W, Tsai HF, Schmidt D, Schardl CL: Relationships among non-Acremonium sp. fungal endophytes in five grass species. Appl Environ Microbiol 1993, 59:1540-1548.

32. Takach JE, Mittal S, Swoboda GA, Bright SK, Trammell MA, Hopkins AA, Young CA: Genotypic and chemotypic diversity of Neotyphodium endophytes in tall fescue from Greece. Appl Environ Microbiol 2012 78:5501-5510

33. Yates SG, Petroski RJ, Powell RG: Analysis of loline alkaloids in endophyteinfected tall fescue by capillary gas-chromatography. J Agri Food Chem 1990, 38:182-185.

34. Dutt JE: Computing probability integral of a general multivariate-T. Biometrika 1975, 62:201-205.

35. Scheffé H: Analysis of variance. New York: John Wiley \& Son, Inc.; 1959

36. Burg MB, Ferraris JD: Intracellular organic osmolytes: function and regulation. J Biol Chem 2008, 283:7309-7313.

37. Bohnert H, Shen B: Transformation and compatible solutes. Sci Hortic (Amsterdam) 1998, 78:237-240.

38. Rodriguez $R$, Redman R: Balancing the generation and elimination of reactive oxygen species. Proc Natl Acad Sci U S A 2005, 102:3175-3176

39. Ahmad P, Sarwat M, Sharma S: Reactive oxygen species, antioxidants and signaling in plants. J Plant Biol 2008, 51:167-173.

40. Hoekstra FA, Buitink J: Mechanisms of plant desiccation tolerance. Trends Plant Sci 2001, 8:431-438.

41. Morgan J: Osmoregulation and water stress in higher plants. Annu Rev Plant Physiol 1984, 35:299-319.

42. Alpert P, Oliver MJ: Drying without dying. In Desiccation and Survival in Plants. Edited by Black M, Prichard HW. Wallingford, UK: CAB International; 2002:3-43.

43. Buitink J, Laessens MMAE, Hernmings MA, Hoekstra FA: Influence of water content and temperature on molecular mobility and intracellular glasses in seeds and pollen. Plant Physiol 1998, 118:531-541.
44. Rolland F, Moore B, Sheen J: Sugar sensing and signaling in plants. Plant Cell 2002, 14:185-205.

45. Couee I, Sulmon C, Gouesbet G, El Amrani A: Involvement of soluble sugars in reactive oxygen species balance and responses to oxidative stress in plants. J Exp Bot 2006, 57:449-459.

46. Deryabin A, Sinkevich M, Dubinina I, Burakhanov E, Trunova T: Effect of sugars on the development of oxidative stress induced by hypothermia in potato plants expressing yeast invertase gene. Russ J Plant Physiol 2007, 54:32-38.

47. Parrent JL, James TY, Vasaitis R, Taylor AF: Friend or foe? Evolutionary history of glycoside hydrolase family 32 genes encoding for sucrolytic activity in fungi and its implications for plant-fungal symbioses. BMC Evol Biol 2009, 9:148

48. Lam CK, Belanger FC, White JF, Daie J: Mechanism and rate of sugar uptake by Acremonium typhinum, an endophytic fungus infecting Festuca rubra - evidence for presence of a cell wall invertase in endophytic fungi. Mycologia 1994, 86:408-415.

49. Ambrose KV, Belanger FC: SOLiD-SAGE of endophyte-infected red fescue reveals numerous effects on host transcriptome and an abundance of highly expressed fungal secreted proteins. PLoS One 2012, 7:e53214.

50. Solomon PS, Waters OD, Oliver RP: Decoding the mannitol enigma in filamentous fungi. Trends Microbiol 2007, 15:257-262.

51. Keller F, Matile P: Storage of sugars and mannitol in petioles of celery leaves. New Phytol 1989, 113:291-299.

52. Tarczynski MC, Jensen RG, Bohnert HJ: Stress protection of transgenic tobacco by production of the osmolyte mannitol. Science 1993, 259:508-510.

53. Hu L, Lu H, Liu QL, Chen XM, Jiang XN: Overexpression of $m t I D$ gene in transgenic Populus tomentosa improves salt tolerance through accumulation of mannitol. Tree Physiol 2005, 25:1273-1281.

54. Chan ZL, Grumet R, Loescher W: Global gene expression analysis of transgenic, mannitol-producing, and salt-tolerant Arabidopsis thaliana indicates widespread changes in abiotic and biotic stress-related genes. J Exp Bot 2011, 62:4787-4803.

55. Sickler CM, Edwards GE, Kiirats O, Gao ZF, Loescher W: Response of mannitol-producing Arabidopsis thaliana to abiotic stress. Funct Plant Biol 2007, 34:382-391.

56. Pilon-Smits EAH, Terry N, Sears T, Kim H, Zayed A, Hwang S, van Dun K, Voogd E, Verwoerd TC, Krutwagen RWHH, Goddijn OJM: Trehalose-producing transgenic tobacco plants show improved growth performance under drought stress. J Plant Physiol 1998, 152:525-532.

57. Karim S, Aronsson H, Ericson H, Pirhonen M, Leyman B, Welin B, Mäntylä E, Palva ET, Dijck P, Holmström K-O: Improved drought tolerance without undesired side effects in transgenic plants producing trehalose. Plant Mol Biol 2007, 64:371-386

58. Garg AK, Kim J-K, Owens TG, Ranwala AP, Choi YD, Kochian LV, Wu RJ: Trehalose accumulation in rice plants confers high tolerance levels to different abiotic stresses. Proc Natl Acad Sci USA 2002, 99:15898-15903.

59. Redillas MFR, Park S-H, Lee J, Kim Y, Jeong J, Jung H, Bang S, Hahn T-R, Kim $J-K$ : Accumulation of trehalose increases soluble sugar contents in rice plants conferring tolerance to drought and salt stress. Plant Biotechnol Rep 2012, 6:89-96.

60. Romero C, Belles JM, Vaya JL, Serrano R, CulianezMacia FA: Expression of the yeast trehalose-6-phosphate synthase gene in transgenic tobacco plants: Pleiotropic phenotypes include drought tolerance. Planta 1997, 201:293-297.

61. Yeo ET, Kwon HB, Han SE, Lee JT, Ryu JC, Byun MO: Genetic engineering of drought resistant potato plants by introduction of the trehalose-6phosphate synthase (TPS1) gene from Saccharomyces cerevisiae. Mol Cells 2000, 10:263-268.

62. Cortina C, Culianez-Macia FA: Tomato abiotic stress enhanced tolerance by trehalose biosynthesis. Plant Sci 2005, 169:75-82.

63. Fernandez O, Bethencourt L, Quero A, Sangwan RS, Clement C: Trehalose and plant stress responses: friend or foe? Trends Plant Sci 2010, 15:409-417.

64. Goddijn OJM, Verwoerd TC, Voogd E, Krutwagen PWHH, de Graaf PTHM Poels J, van Dun K, Ponstein AS, Damm B, Pen J: Inhibition of trehalase activity enhances trehalose accumulation in transgenic plants. Plant Physiol 1997, 113:181-190

65. Eastmond PJ, van Dijken AJH, Spielman M, Kerr A, Tissier AF, Dickinson HG, Jones JDG, Smeekens SC, Graham IA: Trehalose-6-phosphate synthase 1, 
which catalyses the first step in trehalose synthesis, is essential for Arabidopsis embryo maturation. Plant J 2002, 29:225-235.

66. Satoh-Nagasawa N, Nagasawa N, Malcomber S, Sakai H, Jackson D: A trehalose metabolic enzyme controls inflorescence architecture in maize. Nature 2006, 441:227-230.

67. Zhang Y, Primavesi LF, Jhurreea D, Andralojc PJ, Mitchell RA, Powers SJ, Schluepmann H, Delatte T, Wingler A, Paul MJ: Inhibition of SNF1-related protein kinase 1 activity and regulation of metabolic pathways by trehalose-6-phosphate. Plant Physiol 2009, 149:1860-1871.

68. Jiang Y, Chen XM, Liu YJ, Li YT, Zhang HH, Dyson P, Sheng HM, An LZ: The catalytic efficiency of trehalose-6-phosphate synthase is effected by the N-loop at low temperatures. Arch Microbiol 2010, 192:937-943.

69. Paul MJ, Jhurreea D, Zhang Y, Primavesi LF, Delatte T, Schluepmann H, Wingler A: Upregulation of biosynthetic processes associated with growth by trehalose 6-phosphate. Plant Signal Behav 2010, 5:386-392.

70. Delatte TL, Sedijani P, Kondou Y, Matsui M, de Jong GJ, Somsen GW, WieseKlinkenberg A, Primavesi LF, Paul MJ, Schluepmann H: Growth arrest by trehalose-6-phosphate: An astonishing case of primary metabolite control over growth by way of the SnRK1 signaling pathway. Plant Physiol 2011, 157:160-174.

71. Carvalho M: Drought stress and reactive oxygen species. Plant Signal Behav 2008, 3:156-165.

72. Gill S, Tuteja N: Reactive oxygen species and antioxidant machinery in abiotic stress tolerance in crop plants. Plant Physiol Biochem 2010, 48:909-930.

73. White JF, Torres MA: Is plant-endophyte defensive mutualism is the result of oxidative stress protection, Review. Physiol Plant 2010, 138:440-446.

74. Yoshiba Y, Kiyosue T, Nakashima K, YamaguchiShinozaki K, Shinozaki K: Regulation of levels of proline as an osmolyte in plants under water stress. Plant Cell Physiol 1997, 38:1095-1102.

75. Verbruggen N, Hermans C: Proline accumulation in plants: a review. Amino Acids 2008, 35:753-759.

76. Dickman MB, Chen CB: Proline suppresses apoptosis in the fungal pathogen Colletotrichum trifolii. Proc Natl Acad Sci U S A 2005, 102:3459-3464.

77. Blankenship JD, Spiering MJ, Wilkinson HH, Fannin FF, Bush LP, Schardl CL: Production of loline alkaloids by the grass endophyte, Neotyphodium uncinatum, in defined media. Phytochemistry 2001, 58:395-401.

78. Schardl CL, Grossman RB, Nagabhyru P, Faulkner JR, Mallik UP: Loline alkaloids: Currencies of mutualism. Phytochemistry 2007, 68:980-996.

79. Blankenship JD, Houseknecht JB, Pal S, Bush LP, Grossman RB, Schardl CL: Biosynthetic precursors of fungal pyrrolizidines, the loline alkaloids. Chembiochem 2005, 6:1016-1022.

80. Zhang DX, Nagabhyru P, Schardl CL: Regulation of a chemical defense against herbivory produced by symbiotic fungi in grass plants. Plant Physiol 2009, 150:1072-1082.

81. Belesky DP, Stringer WC, Hill NS: Influence of endophyte and water regime upon tall fescue accessions. 1. growth-characteristics. Ann Bot 1989, 63:495-503.

82. Fernandez $\mathrm{O}$, Theocharis $\mathrm{A}$, Bordiec $\mathrm{S}$, Feil $\mathrm{R}$, Jacquens $\mathrm{L}$, Clement $\mathrm{C}$, Fontaine F, Barka EA: Burkholderia phytofirmans PsJN acclimates grapevine to cold by modulating carbohydrate metabolism. Mol Plant Microbe Interact 2012, 25:496-504

83. Theocharis A, Bordiec S, Fernandez O, Paquis S, Dhondt-Cordelier S, Baillieul F, Clement C, Barka EA: Burkholderia phytofirmans PsJN primes Vitis vinifera $\mathrm{L}$. and confers a better tolerance to low nonfreezing temperatures. Mol Plant Microbe Interact 2012, 25:241-249.

84. Rasmussen S, Parsons AJ, Fraser K, Xue H, Newman JA: Metabolic profiles of Lolium perenne are differentially affected by nitrogen supply, carbohydrate content, and fungal endophyte infection. Plant Physiol 2008, 146:1440-1453.

85. Rasmussen S, Parsons AJ, Jones CS: Metabolomics of forage plants: a review. Ann Bot 2012, 110:1281-1290.

86. Chaves M, Maroco J, Pereira J: Understanding plant responses to drought from genes to the whole plant. Funct Plant Biol 2003, 30:239-264

87. Chaves MM, Flexas J, Pinheiro C: Photosynthesis under drought and salt stress: regulation mechanisms from whole plant to cell. Ann Bot 2009, 103:551-560.

doi:10.1186/1471-2229-13-127

Cite this article as: Nagabhyru et al:: Tall fescue endophyte effects on tolerance to water-deficit stress. BMC Plant Biology 2013 13:127.

\section{Submit your next manuscript to BioMed Central and take full advantage of:}

- Convenient online submission

- Thorough peer review

- No space constraints or color figure charges

- Immediate publication on acceptance

- Inclusion in PubMed, CAS, Scopus and Google Scholar

- Research which is freely available for redistribution 